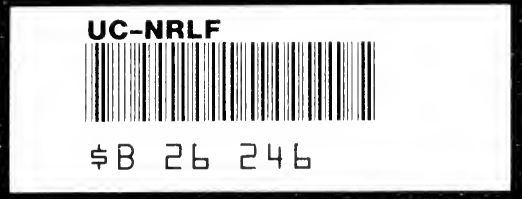




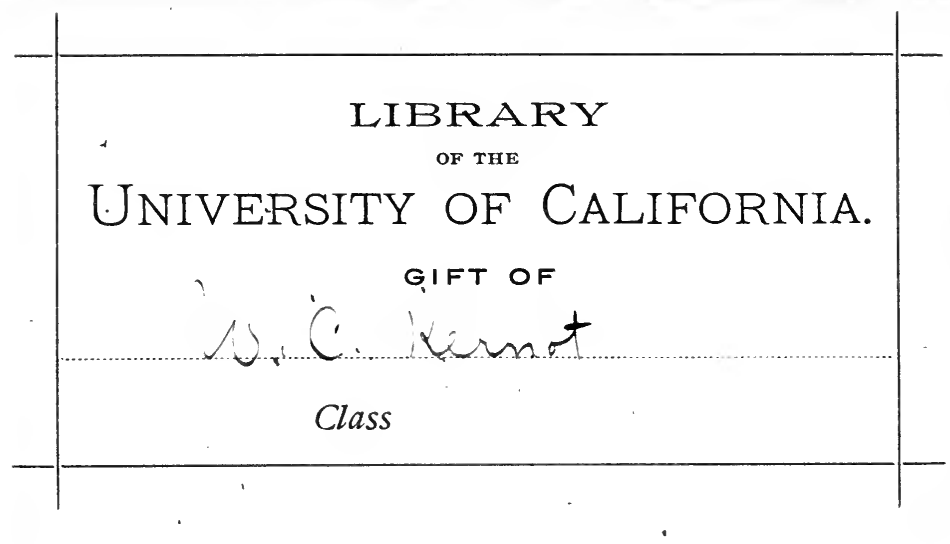




On some Common Errors in Iron Bridge Design. 



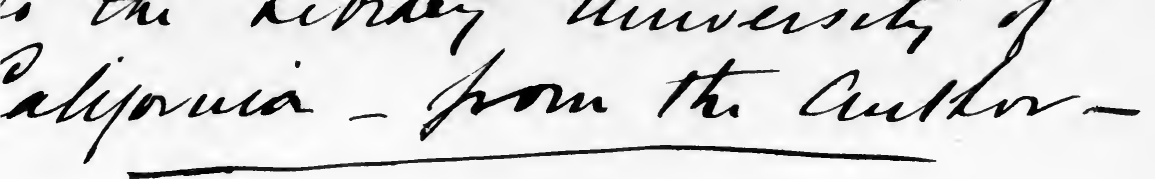

\section{ON SOME COMMON ERRORS IN IRON BRIDGE DESIGN.}

\section{By W. C. KERNOT,}

M. A., M.C.E., M. Inst. C.E.,

M. Ам. Soc. C. E.

Professor of Engineering, Melbourne University.

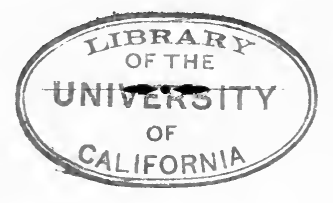

SECOND EDITION.

\section{- ftelhonitr :}

Ford \& SON, Printers, 372 \& 374 Drummond Street, Carlton. 1906. 
$4 k$

$\therefore$
. $x$
0

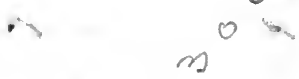

$\alpha^{\circ} \alpha^{6} 0^{\infty}$

$$
4+r
$$




\section{PREFACE.}

The steady though moderate demand for this small treatise and the approaching exhaustion of the first edition have led to the preparation of a second edition, amplified and brought up to date, which the author hopes will meet the approval of the engineering public and aid in the detection and rectification of errors and sources of weakness which it cannot be denied are still too prevalent, especially in structures erected before scientific bridge design received its modern development.

\section{University of Melbourne,}

December, 1906. 



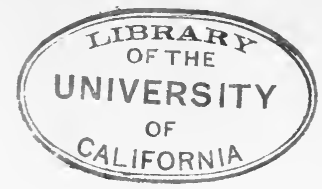

\section{On Some Common Errors in Iron BRIdge Design.}

In the Australian States, as in other parts of the world, there is a large and increasing number of iron (in which is included steel) bridges. These bridges are of ages varying up to more than fifty years. Many of them were designed at a time when the proper mode of proportioning the various parts was but imperfectly understood, while in some the material and workmanship is by no means up to the modern standards. Unlike wine, bridges do not improve with age-on the contrary, corrosion is always going on, sometimes rapidly, but generally very slowly, but no less surely, and is bound sooner or later to cause a perceptible diminution in strength. It is also thought by many that there is a tendency for the metal in course of time to become hard and brittle, and so less able to endure shocks. Thus the bridges are without doubt growing weaker with effluxion of time. Meanwhile the loads they have to endure show a distinct tendency to increase. Steam rollers, traction engines, and other specially heavy loads, undreamt of at the time our earlier bridges were designed, are now common, while locomotives, with the universal call for more power, become constantly larger and heavier, and powerful continuous brakes, unknown when the earlier bridges were built, introduce longitudinal stresses of serious magnitude. From these combined causes it is plain that the margin of safety is steadily diminishing, and it is only a question of time for the point of absolute danger to be reached.

Again, calculation shows that some parts of the older bridges are excessively and unnecessarily strong, while other portions are weak, and that the general arrangement of parts is often far from the most economical.

It appeared, therefore, that a criticism of existing bridges would be useful not only to the designer of new structures anxious to avoid the defects of the older ones, but also, and 
perhaps in an even greater degree, to the man who has received a legacy of imperfect structures from his predecessors, which he is desirous of utilising as far as possible by judicious repairing and local strengthening, for it is to be noted as a good point of many of our defective bridges that they are like chains, most of the links of which are abundantly strong while occasionally a very weak one is found, which governs the strength of the whole, and that thus a comparatively inexpensive local reinforcement may improve the whole structure to a very large and valuable extent.

I shall now proceed as briefly as is consistent with clearness to point out what I consider to be the principal errors in structures that have come under my notice, and indicate how their defects may be remedied, if remediable, in existing, and avoided in future structures.

I. Disproportion of foundation area to load carried. - If a foundation is too small it gives way partially or wholly, injuring or destroying the structure; if too large it stands, but represents waste of money. In every instance, however, some slight yielding when the load is applied takes place, and it is desirable, especially if continuous girders are employed, that all the supports should yield equally. Hence all foundations should be proportioned to the load carried - that is to say, under full load the pressure per unit area on the supporting material should be throughout equal. In calculating this pressure, it is to be remembered that it is not the total load on the foundation surface that is to be considered, but the excess over the load that existed previously. For example, at the great Hawkesbury Bridge, N.S.W., it has been stated that the pressure on the foundation is ten tons per square foot, and this is obtained by dividing the total weight of the structure by the area of foundation. But in order to reach the depth required a very large quantity of earth had to be removed, and the foundation was relieved to that extent. The true or effective pressure on the foundation is therefore the difference between these two amounts, and actually is only five tons per square foot. This, I submit, is the correct way of stating foundation pressure.

There is a further qualification, however, and that is the allowance for the effect of friction of earth upon the sides of a 
bridge cylinder or caisson, and if this be taken into account, the pressure on the base is still further reduced. This friction is somewhat variable, and has been stated as high as 800 and as low as 50 lbs. per square foot in different strata.

Directing our attention to existing structures, great discrepancies appear in the size of cylinder foundations, not only between one structure and another, but between different piers of the same structure. For example, the Intercolonial Railway Bridge at Albury consists of two continuous spans of 160 feet each, carried on three piers, each consisting of two cylinders of ten feet diameter. The centre pair of these cylinders carry I0-I6ths of the load, while the two end pairs together carry only 6-r6ths. Thus, while two cylinders carry a load represented by the number ten, four of equal size are provided to carry a load of six only, and these four are further surrounded by earth to a much greater height than the central ones, and therefore receive greater frictional support. It cannot, I think, be disputed that the bridge would have been both cheaper and safer had the end cylinders been reduced to six feet diameter, or even less, for then any yielding would have been approximately equal throughout, and the distribution of bending moment in the continuous girders consequently undisturbed. Similar remarks will apply to the Railway Bridges at Wagga, Bathurst, and Aberdeen, described in the Report of the Royal Commission on Railway Bridges, N.S.W., I886. In all of these the terminal cylinders, though carrying less than half the load, and more favourably circumstanced in other respects, are just as large in diameter as their heavily loaded companions (see Fig. I), which represents to scale the railway bridge at Aberdeen, N.S.W. A reference to numerous successful cylinder and caisson bridge foundations leads to the conclusion that the subjoined are safe foundation pressures, the most unfavourable combination of load, wind and flood, being employed in the calculation. Rock Io tons per square foot at least. Fine compact sand at considerable depths, 6 tons per square foot. Very good clay 5 tons per square foot. Ordinary sand, clay, or loam, I to 3 tons per square foot. Knowing, then, the superincumbent load and the nature of the material, there should be no difficulty in proportioning the cylinders of 
future bridges. As for those in existence, nothing can be done, but as they usually err on the side of excess, there is not much cause for alarm.

2. Excessive and disproportionate size of columns.-By the term column is meant that part of the structure extending from the foundation to the girder seat. Its size is often made equal to that of the foundation, but there is no necessity that this should be the case, for while the size of the foundation depends on the resistance of the material upon which it rests, that of the column depends upon the material of which it is made, and which sometimes offers a greater resistance per square inch than the foundation does per square foot. For the sake of lateral and frictional support, the cylinder is usually, and properly, carried up the full size from the foundation to the surface of the ground. Above this, however, there is no reason why it should not be as economically designed as any compression element of the superstructure. In many of the older bridges the columns are of most unnecessary size, adding seriously to the cost of the structure, and impeding the flow of water in the case of river bridges in an undesirable manner. This is certainly the case with the older New South Wales railway bridges already referred to, and also with some in Victoria. As examples of what has been successfully done in the way of reducing this part of the structure to reasonable and economical proportions, two structures may be cited. The first is the Johnston Street Bridge, Collingwood, near Melbourne, shown in Figs. 2 and 3. This is a bridge built about 30 years since, consisting of three spans of nearly 60 feet each, having as intermediate supports wrought iron columns filled with concrete, which for slightness present a most extraordinary contrast to the usual practice at the time it was built. Their dimensions are as follow :-

Height from top of cast iron cylinder

to girder seat ........

Diameter . . . . . . . . . . . . 2 feet

Thickness of metal . . . . . . . 5-16th inch

Dead load for each column ... . . . 40 tons

Live load for each column ...... 50 tons

Each pair of these columns supports an area of decking 70 feet long and 32 feet wide. 
The proof of the practical success of these columns is in every way most conclusive, for not only is the bridge on an important main road with heavy traffic, but it is also at the part of the Yarra where the hydraulic conditions are of the severest kind. During the great flood of July, I89r, when two iron bridges were washed away and hundreds of suburban dwellings inundated, the water stood at the level shown in Fig. 2. The gradient of the flood surface for 50 chains above the bridge was at the rate of over 5 feet per mile, the hydraulic radius about 30 feet, and floating timber and other wreckage abounded. Nevertheless these slender columns stood absolutely uninjured, and that, although the bracing between them is by no means as massive as, in the author's opinion, it should be.

The second example is the bridge carrying the North-Eastern Railway over the Racecourse Road, Flemington, near Melbourne. The railway is double line and is traversed by a busy suburban traffic propelled by tank engines of 49 tons weight. The bridge is situated at the entrance of the Newmarket Station and is exposed to the constant action of the Westinghouse brake. There are two spans of $5 \mathrm{I}$ feet each (discontinuous) four main girders to each span, and the central support consists of four columns each made of four $3 \frac{1}{2} \times 3 \frac{1}{2} \times \frac{1}{2}$ angles of mild steel, with single riveted lacing. The foundations are of Victorian bluestone, a 3 -inch cube of which crushes with 40 tons pressure, and are $2 \frac{1}{2}$ feet square for each column. The compressive stress on the metal of the angles is 4 tons per square inch. The columns are ${ }_{5}$ feet high from, stone foundation to girder seat and are 18 inches square.

Strange to relate a second railway, carrying a practically identical traffic crosses the same road at a short distance, and here the columns are of cast iron filled with cement, $2 \mathrm{ft}$.

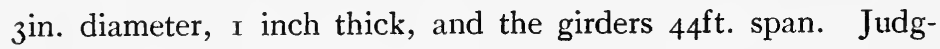
ing from experiments made with the University testing machine it would take 300 tons to crush a column of the former bridge and over 2000 tons to crush one of the latter, and yet the latter carries a smaller load than the former.

As a further instance of economical design, Kinzua Viaduct, New York State, U.S.A., may be quoted, a section of a wrought iron column of which is shown in Fig. 4. This struc- 
ture, after carrying constant railway traffic for nearly 20 years, has, owing to increase in weight of locomotives, been replaced by a more massive one of somewhat similar design. Two of these columns form the support intermediate to a span of $6 \mathrm{I}$ and one of 38 feet, carrying a main line of railway $4 \mathrm{ft}$. $8 \frac{1}{2} \mathrm{in}$. gauge. Each column is $279 \mathrm{ft}$. high and is braced laterally at intervals of $3 \mathrm{Ift}$. Further comment is needless to show how excessively wasteful bridge columns in Australia have been in cases too numerous to mention.

3. Imperfectly-braced Piers.-Piers of bridges often consist of two or more columns which individually possess very little power of resisting horizontal forces such as wind or flood pressure, tending to overturn them. To give them this power they are braced together by horizontal or diagonal members as for example Fig. 3, which represents the bracing of a pier of the bridge shown in side elevation in Fig. 2. Of this bracing there are many varieties of which some are defective from the point of view of calculation of strength, while some are unnecessarily costly in construction. The former may involve danger, the latter represent money wasted, and consequent over-capitalisation.

In the example shown the horizontal members are massive and costly plate girders consisting of several sections of iron and a multitude of rivets. The diagonals are rather light angle irons rivetted together where they cross. All the members being capable of resisting both compression and tension, the arrangement is guilty of the fault of redundancy, which will be more fully dealt with later on in connection with girders. The result of this is that the stresses cannot be accurately computed except on assumptions as to workmanship that may possibly be far from the truth. Were the horizontals $\mathrm{A}$ B and C D omitted, and the diagonals made stouter, the calculation would become simpler and more certain, while cost would be reduced, and risk of damage by floating bodies to which the present slight diagonals are liable would be diminished.

Another bridge over the same river has bracing of the same general design, and open to the same objections, but with the further fault that there is a complex and costly joint at $\mathrm{O}$, so 
arranged that $\mathrm{A} \mathrm{O}$ and $\mathrm{O} \mathrm{D}, \mathrm{BO}$ and $\mathrm{O} C$, are not in the same straight line. Hence serious bending actions are involved, and the whole joint has a tendency to rotate. The diagonals also are so flimsy that they may be shaken by the pressure of the hand, and a very small blow from a floating $\log$ would infallibly bend if not break them. In a third bridge -namely, that at Victoria-street, a greatly preferable arrangement is found. One diagonal in each panel is omitted, for example, G B, B C and $\mathrm{C} \mathrm{F}$ are abolished, and the remaining parts, both horizontal and diagonal, made of stout $\mathrm{T}$ iron, much stouter than the diagonals in the other bridges. The calculation of stress thus becomes perfectly definite, the workmanship is reduced to a minimum, and there are no flimsy parts liable to damage by floating bodies. See Fig. 50.

Piers of tall trestle viaducts, clock and look-out towers, and lighthouses are often framed on the lines of Fig. 3, with fairly massive horizontals and light diagonals, capable of bearing tension only. This construction has had large developments in railway viaducts in America, and also near Adelaide and over the Werribee at Melton in Victoria. There is no objection to it provided these light rods are out of the way of floating bodies, and, further, are so adjusted that when one is acting, that crossing it is just free from stress. This is secured by providing one or both diagonals in each panel with screw or wedge adjusting devices, and when the structure is finished and loaded, carefully adjusting them to secure the required state of stress.

In several structures, however, that have come under the notice of the author, these adjusting devices have been omitted, and the diagonals, thin flat ribands of metal carefully riveted on before the structure was loaded. At first all seemed well, but as soon as the load came on, the columns shortened elastically, the diagonals became loose, and the structure lurched over from side to side under varying lateral forces to an extent, probably not exactly dangerous, but certainly alarming to the public and both unsightly and undesirable. Then comes an altercation between the engineer and the contractor, the former accusing the latter of neglecting to have the diagonals tight when riveting them on, and the latter denying 
the charge. The moral is that adjusting devices should be applied or else the diagonals put on under initial stress so as to be lengthened to such an extent that the compression of the columns will not slacken them. The former alternative is practically the more certain and effective.

The question of what value should be allowed for wind or flood pressure has not received the attention it deserves in text books. For the guidance of designers the following rules based a fairly wide experience are suggested as reasonable.

I. Take the wind pressure as 2olbs. per square foot on a flat surface at right angles to the direction of the wind.

2. Assume a cylindrical surface as offering half the resistance to wind that a flat surface does.

3. Ignore any sheltering effect of one part of the bridge on another. For instance, in a bridge having two main girders allow full wind pressure on each, unless very close together.

4. Adopt a factor of safety of 4 for strength and 2 for cases where stability only is concerned.

5. In cases of extraordinary exposure, as in structures of heights over rooft., or placed near the sea, increase the stability and strength by an extra allowance varying according to judgment up to 50 per cent.

For further information, consult the author's papers on Wind Pressure in Vols. V. and VI. of the Australasian Association for the Advancement of Science. For flood pressure, calculate in the same way as for wind. The velocity of floods though apparently much higher, rarely exceeds $8 \mathrm{ft}$. per second, at which speed the pressure on a flat surface at right angles to the current is 6olbs. per square foot. Flood pressure will rarely be found to involve serious risk of overturning. Bridges destroyed by floods usually fail through undermining of foundations, and often fall upstream, showing that the actual pressure of the current had nothing to do with the result.

In Fig. 3 it will be noted that the bottom panel or space below the line E F is unbraced. This is the usual practice, and the author is not aware of any disaster having occurred due to it. Still it is not altogether satisfactory, and he would 


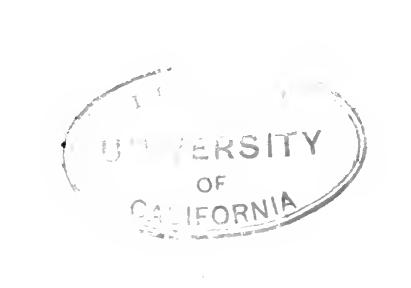


certainly prefer to continue the bracing down at least to the bottom of the river.

It is advised that new structures should be built to conform with above standards for wind and flood, but not for both at the same time, such a contingency being almost infinitely remote, and that existing structures if more than 25 per cent. below should be strengthened, and that slack tension diagonals should be provided with proper adjustments.

4. Girders supported in an unfavourable manner.-Under this heading come many defective arrangements. The first of these is when a girder is supported at the extreme end, it being possible to support it at a more favourable point. It does not seem to have been generally recognised by engineers that the extremity of a girder is a most unfavourable point of support, giving rise to bending moments and shears of maximum value, and therefore should not be adopted except under the most cogent conditions. If the points of support of a uniformly loaded beam are moved towards the centre, the most surprising diminution both of bending moment and shear takes place, and when the supports are distant from the ends by .207 of the length the maximum bending moment is reduced to .172 and the maximum shear to .59 of what it is when the supports are terminal. As in the great majority of beams including rectangular sections of timber and rolled girders of usual proportions, the strength is regulated by the moment and not by the shear, this means that a uniform beam supported at what may be called the "efficient points," is very nearly six times as strong as a similar one supported at the ends, the load being uniformly distributed. With a live or variable load, such as a crowd, the advantage is not so great, the stress range being somewhat increased, but even allowing for this in accordance with the Weyrauch vibration formula, the strength of a beam carrying an equal live and dead load-a very usual case-is increased about threefold by its being supported at the efficient points instead of the ends. Thus it will be seen that there is an enormous advantage in supporting both main and cross girders at their efficient points, or as near to those points as is possible, and this is true in all cases but most especially so when the dead load is large. 
Should it be obligatory to support the beam at one extremity, the position of the other support being optional, the efficient point is found to be .29 of the length from the other end, and the maximum bending moment is almost exactly one-third of what it would be were both supports terminal, the load being uniformly distributed.

Should it be inconvenient to adopt so large an overhang as above-mentioned, considerable advantage may still be obtained with a very moderate amount. For example, a uniform beam uniformly loaded and supported at points one-eighth of its length from the ends endures a maximum bending moment of only one-half of what it would if supported at the extremities.

The surprising effect of placing supports of beams in favourable, instead of unfavourable, positions has been little noted by engineering writers. In his "Introduction to the Mathematical Theory of Stress and Strain of Elastic Solids," Dr. B. Williamson, of Trinity College, Dublin, works out a few cases, but little prominence is given to the matter, and the book is one not likely to be known to engineers. Hence it appeared desirable to give, see Figs. 5 to 9, graphic illustrations as to how the strength of a uniform beam under a uniform load is increased by a judicious location of the supports. The shaded areas represents the relative depth of water, earth or other uniformly heavy material the same beam is capable of carrying when supported in the ways shown. It seems strange that Fig. 5 should be so common, and Figs. 6 and 9 so unusual.

Of course bridge loads are not always uniform, and beams are often made with their strength varying with the bending moment (but with the general use of rolled girders of large size this is becoming more unusual), nevertheless there can be no doubt that even with ordinary railway or road loading much advantage might be gained by adopting Fig. 6 instead of Fig. 5, and Fig. 9 instead of Fig. 8. Assuming the latter to represent three main girders supporting a cross girder, Fig. 9 will have the further advantage of equalising the loads on the main girders, and so simplifying construction.

As an instance in which an overhanging end might have been advantageously applied certain bridges on the Melbourne and Coburg Railway may be cited. Here, as shown in Fig. 


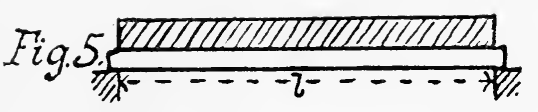

Bending Relative

Moment. strength.

$\cdot 125 w^{2} \quad 1$.

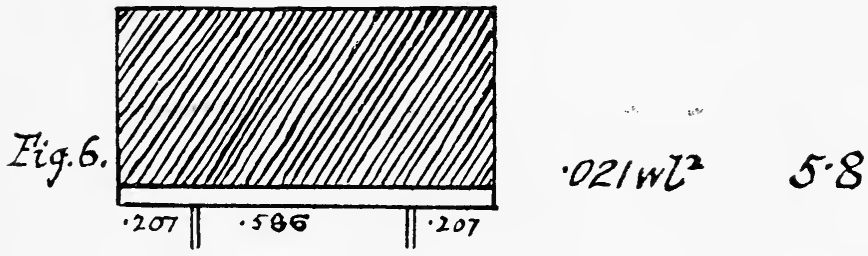

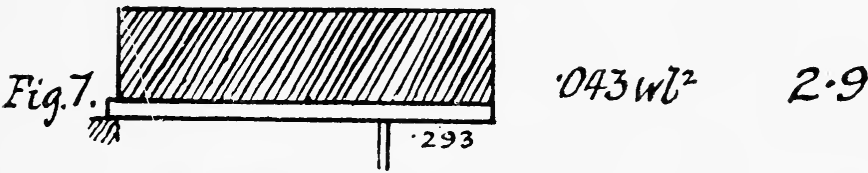
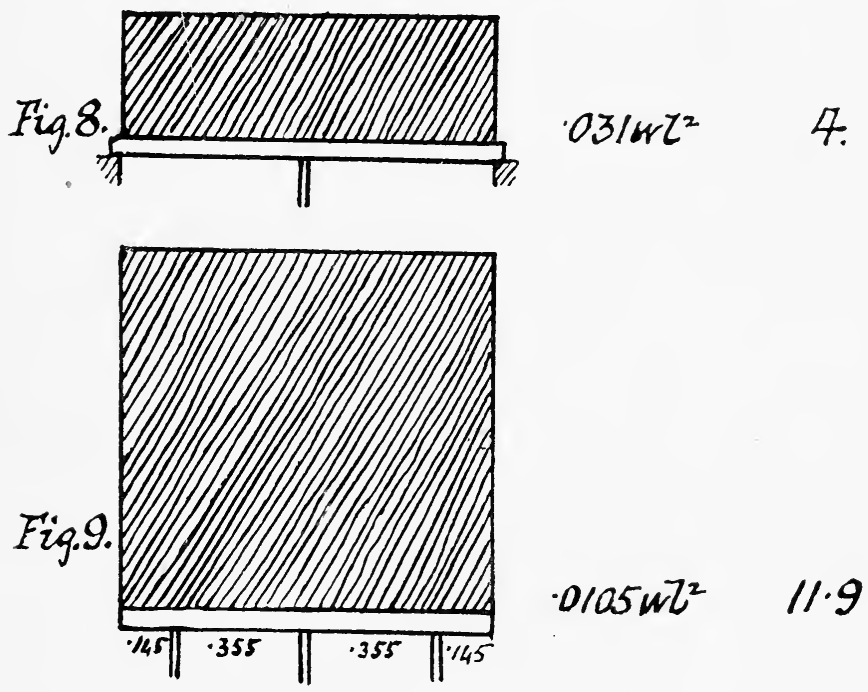
10, the terminal support of the girder is a brick pier imbedded in the embankment, and the girder seat is surrounded with earth in an undesirable way. By moving the pier to the position shown in Fig. II, the bending moment would be reduced, and the girder seat rendered accessible.

A case of unfavourably arranged support is illustrated in Fig. I2, which represents two bridges each crossing several lines of railway in Yarra Park, Melbourne. The girders are of the lattice type, supported at the ends by a double system of standards or legs. Calculation shows that the compressions on the diagonals $\mathrm{AB}$ and $\mathrm{CD}$ are equal. But the tension on $\mathrm{AC}$ is equal to the compression on $\mathrm{AB}$ as their horizontal resolved parts balance at $\mathrm{A}$. Hence the vertical resolved part of $\mathrm{AC}$ balances that of $\mathrm{CD}$ at $\mathrm{C}$, and the leg $\mathrm{CE}$ carries no weight whatever, except the actual small floor load at $\mathrm{C}$.

Now, had the bridge been arranged as at Fig. I3, the main girder would have been shortened by ten per cent., the stresses throughout the remainder would have been reduced considerably, the leg FG would have been saved and the whole structure largely reduced in length, thus economising flooring, hand-railing and area of ground occupied. If further the ramp had been started at $\mathrm{H}$, which the loading gauge of the railway would permit, the length of decking and handrail would have been reduced still further making a saving for the whole bridge of no less than 18 feet.

A third case of unfavourable support is where the girder seat is not placed centrally to the cylinder or column. This causes the stress to be greater on one side of the column than the other, and involves a tendency for the column to lean over if in soft ground. An instance of this is to be seen in an important bridge illustrated in "Engineering," vol. 43, p. II 7 .

Such errors as these are usually irremediable in existing structures. It is desirable, however, to guard against their repetition in future designs.

5. Imperfect expansion apparatus.-Variations of temperature affect all metal structures, and unless properly provided for may cause extra stresses of serious amount in the metal work and dislocation of the brick work or masonry of the supports, such dislocation, unfortunately, being only too 
apparent in not a few existing structures. The extreme temperature range in Melbourne from the Observatory thermometer records is about $150^{\circ}$ Fahrenheit, but it is not probable that the change of temperature of considerable masses of metal work such as used in bridges will be more than $120^{\circ}$. As iron and steel expand not quite one part in 800 between freezing and boiling, a range of $180^{\circ}$, the expansion for $120^{\circ}$ will be one part in $I 200$ or $I$ inch in roo feet. This simple and easily remembered rule is safe for the Victorian climate, but would not suffice for places such as New York, where the temperature range is greater in both directions than in Melbourne.

A metal structure then should be anchored or fixed at some definite point and be allowed free movement everywhere else. The point of anchorage may advantageously be near the centre, so as to divide up the motion. If this is not convenient the anchorage should be at the firmest or most solid support. If for example one end of a bridge be on solid rock and the other on a tall and somewhat flexible support, the former should be made the anchorage. At the Victoria Street Bridge, near Melbourne, the opposite course was adopted and the whole bridge was thrown somewhat out of position by movement of the support, involving the necessity of its being detached and moved back to its original position-a troublesome operation.

Girders of less than too feet span are usually supported on planed surfaces of metal which slide one upon the other. In some cases pressures of over a ton per square inch have been imposed on such surfaces with success, but usually the pressure is much less. Larger bridges are as a rule supported on rollers and it is desirable that these be of ample diameter and so placed as not to be choked up with dirt or injured by moisture. Rollers 4 inches diameter are allowed $\frac{1}{2}$ ton load per inch length by good American authorities, but this pressure is often exceeded in English practice and apparently with impunity. Whether the sliding plates or rollers should be surmounted by a rockng arrangement is a point on which practice varies. In theory the rocker is undoubtedly correct, giving a perfectly definite point of support, and obviating the unequal 
pressure on the rollers due to the slope of the deflected girder. Many excellent and experienced authorities however omit it.

It is often forgotten by bridge designers that expansion takes place transversely as well as longitudinally, and that roller systems should be arranged accordingly. One point of support being fixed, all the others should he provided with rollers acting in directions radiating from the fixed point.

Tall thin columns, such as those at Johnston Street Bridge, previously referred to, do not need expansion arrangements as a rule, the column 'itself being capable of springing an inch or two without injury. In dealing with the expansion arrangements of existing structures, I would suggest that they be kept clean and lubricated and protected from dust and moisture, and that all impediment to free motion be removed, and for this purpose they should always be as accessible as possible.

We next have to consider the main girders, constituting a large and costly part of the structure. These are of various types, including plate girders, box or tubular girders, closely latticed girders of the type used 40 years ago, and the many modern forms of open girders including the $X$ girder, the $\mathrm{N}$ girder, the $\mathrm{W}$ or Warren girder, the Pratt and Whipple girders so deservedly popular in America, and of late years frequently adopted by English engineers, and other forms too numerous to mention. Some of them are of equal depth throughout, the top and bottom surfaces being parallel, while others vary in depth, having one or sometimes both surfaces curved. To discuss all these various forms in detail would require a very large volume indeed, far beyond the dimensions of the present brochure. All that can be here attempted is to clearly state the leading principles of strong and economic construction, and indicate how they have been transgressed in times past. These are as follows:-

(a) In beams or girders having continuous plate webs the material should be concentrated as far as possible from the neutral axis so as to give a maximum moment of resistance, and only sufficient material be left in the connecting web to enable the whole mass to act as one beam.

(b) The web should be sufficiently stiffened or reinforced 
so as to enable it to bear transverse compression at points of support, or of heavy isolated load.

(c) In open web girders the structure should consist of a continuous series of triangles connecting the points of application of external force, the sides of which should be perfectly straight, and the angles common, and which should be so arranged that determinate equations of equilibrium may be obtained for every angular point.

(d) The various bars composing the frame should be proportioned to the stress they undergo, should be efficiently jointed, and if in compression should be of such a section as not to evade their duty by lateral bending or wrinkling.

(e) In all forms of girder no absolutely unnecessary material should be used in any part, and the proportions and arrangements of parts should be such as to give the greatest possible strength for a given expenditure in material and workmanship. It is to be noted that workmanship usually costs much more than material, and that therefore in girders of moderate size, in which the weight of the girder itself forms but a small portion of the total load, simplicity and ease of construction should be sought even at the cost of a moderate increase in weight.

Let us now see how existing structures fail to comply with the above conditions. In connection with main and cross girders the following errors have come under my notice.

6. Insufficient depth.- The extreme top and bottom elements, or chords as they are generally called, of all structures performing the functions of a beam are stressed in inverse proportion to their distance apart. Hence the deeper the girder the less the stress upon, and requisite sectional area of these parts. As a matter of pure and bald theory the quantity of material in the web is independent of the depth, so that the most economical girder is one infinitely deep with chords infinitely small and web infinitely thin. Such a result as this is of course valueless as a guide to practice except as showing 
that as ample a depth as other considerations permit should be chosen.

For many years English engineers, following apparently the example of Fairbairn, adopted depths of I-I2th to I-I $5^{\text {th }}$ of the span-involving very heavy chord sections. The Americans, however, showed that it was possible to follow theoretical indications much more closely without incurring practical difficulties, and erected many efficient and economical structures with depths of $\mathrm{I}-5$ th to I-Ioth, the average being about I-8th. Of late years English practice has been approaching to American, though somewhat hesitatingly. This is of course in cases when the depth is not restricted by such considerations as head way or flood level.

As practical illustrations of the defect of insufficient depth, I would refer to, first, the earlier foot passenger bridges over the railways in the vicinity of Melbourne. These are excessively shallow Warren or lattice girders surmounted by gas pipe handrails, which in no way add to the strength. A model of one of these at the Prahran Railway Station was made and broken down at the University, and also a model containing the same metal, of decidedly simpler construction and double the depth. The latter was found to be 70 per cent. stronger than the former, and further, had the advantage of dispensing with the handrail, being itself deep enough for the purpose of a parapet (see Figs. I4 and I5).

The cross girders of the recently erected Tower Bridge, London, constitute another example of the same peculiarity, having a depth of only I-2oth of the span. Consequently the chords are enormously massive, consisting of, in some places, seven layers of plates riveted together, an undesirable arrangement, as it is very difficult to effect satisfactory riveting through so many superposed layers of metal, and, further, there is some doubt as to whether the outer layers really do their fair share in resisting the bending moments.

Had the Tower Bridge cross girders been supported at the efficient points (Fig. 6), which lie at the edge of the footpath, the reduction in material and weight required would have been enormous, and it is not clear that there is any insuperable objection to this being done. As examples of excessive shal- 
lowness and most unfavourable mode of support these girders are very notable.

This defect is obviously incurable in existing structures.

7. Unfavourable disposition of material for enduring bending moment.-This is an infraction of requirement $a$ on page I 7, and is occasionally seen in the older type of box girder. A notable example is the Railway Bridge at Penrith, N.S.W., the section of which is shown in Fig. I6. Here there are four chords instead of two, and those nearer the neutral axis represent a most unfavourable disposition of material. The intermediate chords are roft. apart and the extreme ones I 3 . Consequently, first, the stress on the intermediates is only IO-I $3^{\text {ths }}$ of that on the extremes, and as it acts at only IO-I $3^{\text {ths }}$ of the distance from the neutral axis, the value of every square inch of metal is only $\frac{10^{2}}{13^{2}}=\frac{100}{169}$ or not much more than half of what it would have been if placed at the extreme distance. In this way the bridge is loaded with a vast quantity of metal which performs only about 60 per cent. of the duty it should. Further, this arrangement involves the existence of cells i 8 inches square, and nearly 6ooft. long, which are most objectionable from the point of view of inspection, painting and repair. Fortunately, this form of girder is now quite obsolete, so the error is not likely to be repeated.

8. Uniformity of chord section throughout the length.This uniformity is justifiable on grounds of simplicity in rolled beams and the smaller varieties of built girders where a pair of angle bars of convenient size suffices for the maximum chord section. But when one or more plates have to be added, to carry these throughout the whole length regardless of variations of chord stress is absurd. In some of the earlier plate girder bridges on the Victorian Railways this has been done to a most remarkable extent. At Kororoit Creek, on the Geelong Railway, there is a double line bridge of 8 oft. span, the chords of the girders of which consist of two $3 \frac{1}{2} \times 3 \frac{1}{2} \times \frac{3}{4}$ angles and three $24 \times \frac{3}{4}$ plates continuous throughout, and representing an enormous waste of metal towards the ends of the girders. As a pleasing contrast to this the new steel bridges over the Inkermann and Balaclava Roads on the Brighton Railway, 

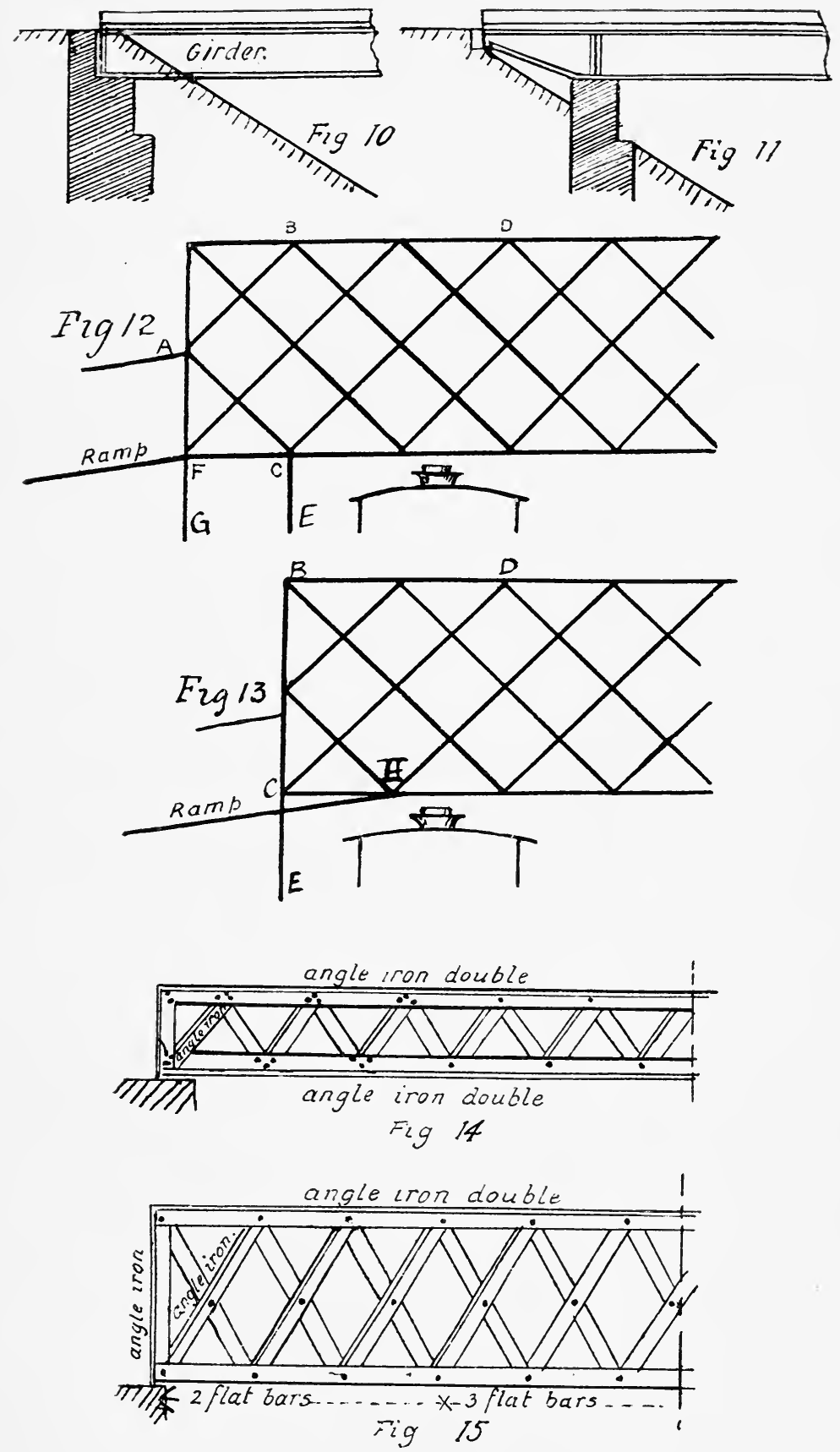
near Melbourne, may be noted. Here the plates are arranged just as the stress requires and for the last few feet of each end are omitted, the angle bars forming the whole chord. Figs. 17 and 18 .

9. Insufficient connection between chord's and web.-The stress in the chord of a plate web girder is given with approximate accuracy by dividing the bending moment by the depth. If this stress be determined at two points say one foot apart, different values will be obtained, the difference between which will be the horizontal or longitudinal shear for that foot in length tending to separate the chord and web. This has to be resisted by the rivets. As the bending moment varies rapidly near the supports, and slowly near midspan, this shear will vary correspondingly. Hence, for equal strength throughout, the pitch of the connecting rivets should vary from the centre to the ends, being very large at midspan, and becoming smaller and smaller as the supports are approached. To carry this out exactly as calculation requires would involve too much complicated measurement for practical conditions, hence one or at most two variations of pitch must suffice, portions of the work being a little over-riveted to secure uniformity. The great Penrith Railway Bridge, N.S.W., shows a notable neglect of this requirement. The riveting at the point $A$ in Fig. 16 being small and uniformly pitched throughout, the rivets are seriously over-stressed for a distance of 40 feet on each side of the piers, and for 10 feet at each end of the bridge (which is continuous over three equal spans). This grave defect was discovered by Professor Warren of Sydney University and verified by the writer. It is fully dealt with in the Report of the Royal Commission on Railway Bridges of N.S.W., I886, and the proper remedy, viz., the replacement of the $\frac{3}{4}$ inch rivets by I inch rivets for the distances mentioned, pointed out. But though this effective remedy could be applied at a mere nominal cost and without any interruption of the traffic, the N.S.W. Railway authorities have persistently refused to yield to the urgent representations of the. Royal Commission, of Professor Warren, and of the writer. A new bridge is fortunately now being built, and the old bridge is in future to be used for road traffic only-for which it is amply strong. 
In the later work of the Victorian Railway Department this variation of horizontal shear has been consistently recognised as is evidenced by the varying pitch of the rivets in the girders on the bridge over the Yarra on the Port Melbourne Railway and elsewhere. The considerations applying to the row of rivets connecting the web and chord angles of these girders also apply to those connecting the chord angles with the chord plates, and a similar variation of pitch is required here. It is to be noted, however, that these latter rivets perform a smaller duty than the former and so may be smaller, or at larger pitch without reducing the strength of the girder - Strange to say in Penrith Bridge these rivets, $B$ in Fig. 16 , are larger than those at $\mathrm{A}$, though dealing with the shear consequent upon the stress variation in a portion of the chord only, while those at A deal with the whole-a notable anomaly. It is to be added that the stress on the vertical rows of rivets in a plate web is identical with that in the contiguous portions of the horizontal rows, and that the diameter and pitch should be the same for both. To illustrate this point Fig. 19 has been prepared, representing a theoretically riveted gircler with terminal supports and uniformly distributed load. Existing girders ought to be examined and computed to see if there is any weakness as to horizontal and vertical shear, and, if there is, rivets should be cut out a few at a time, holes enlarged and bigger rivets inserted, as recommended by the Royal Commission in the case of Penrith Bridge.

I0. Verticai stiffeners absent or wrongly placed.-Requirement $(b)$, page $\mathbf{r}_{7}$. These vertical stiffeners are added at intervals along the web of a plate or box girder for the following purposes:-

I. To prevent the thin web from being crushed by the local vertical pressure due to the reaction of a support or a concentrated load.

2. To check the tendency of the web to buckle under the diagonal compression that pervades it, being most intense near supports and least midway or thereabouts between them.

To comply with the former condition we need a massive vertical pillar at the end of every ordinary girder, and a still 
more massive one at the piers of continuous girders or those with overhanging ends.

Should a very heavy concentrated load, as for example a large column in a building, be imposed at any particular point, this column should be continued as a vertical stiffener to the bottom of the girder. This case does not howerer often occur in bridge-work.

These stiffeners are usually made of uniform section from top to bottom of the girder. This may be justified by convenience of construction, but is not required for strength. As we pass from the bottom to the top of the girder at a point of support, or from the top to the bottom at a point of concentrated top load, the compression in the vertical gradually discharges itself into the web in the form of a shear, or its equivalent, a set of diagonal compressions and tensions, and thus dies away. Hence the vertical at a support should be of the full section required by the reaction of that support at the bottom and diminish to nothing at the top, and that at a concentrated top load, of full section for the load at top diminishing to nothing at the bottom. In large girders this fact may be made use of to save material.

The other use of verticals in plate girders is to prevent the web from buckling or being thrown into waves by the diagonal compression due to the shear. Rankine in his "Civil Engineering " treats the web as a long column tending to buckle under the diagonal compression, and measures the length on an angle of $45 \mathrm{deg}$. between top and bottom chords, or between vertical stiffeners, whichever happens to be the smaller. He then applies the excessively high safety factor of six. There are two most serious errors in this treatment. First, the diagonal tension, which is approximately equal to the diagonal compression, has a powerful tendency to prevent buckling or undulation and so improve matters, and second, to apply a safety factor of six to a long column, whose failure is due to lack of stability and not of strength is unscientific as is shown in my paper on this subject in the "Transactions of the Royal Society of Victoria," Vol. XV., p. I4. There is no doubt that the resistance of such a web to buckling is at least five times as great as the Rankine treatment will allow, and this conclusion is confirmed by Pro- 
fessor Warren's elaborate analysis of the web stresses of Penrith bridge, in the Royal Commission Report previously quoted. It is there shown that, according to Rankine, the safety factor of some parts of the web is less than unity under ordinary traffic, and yet this bridge has now been in existence for more than thirty years and has shown no sign of buckling.

To determine the exact strength of a thin plate web against buckling is a question of much difficulty and obscurity, but there is no possible doubt that it is immensely greater than Rankine's imperfect method of computing indicates, and that in a vast number of instances the thinnest metal that it is desirable to use from the point of view of corrosion and practical convenience of construction is abundant to resist the tendency to buckle due to the shear.

The following rules may be laid down as sound for arranging verticals, and proportioning webs.

I. A vertical pillar at each point of support of section proportioned to the reaction of that support should extend from bottom to top of the web, but it needs the full section only at the bottom and may taper to nothing at the top.

2. This pillar should be placed fairly on the centre of the support and not as is sometimesseen at or near one edge.

3. The web should have a vertical sectional area of one square inch for not more than 2 tons of rertical shear for wrought iron, and $2 \frac{1}{2}$ tons for mild steel.

4. Vertical stiffeners of $T$ section should be placed wherever any considerable concentrated load is imposed on the top chord.

Bridges defective in these respects should be reinforced by riveting on the necessary additional parts.

Leaving the girders with continuous plate webs we next have to consider those in which the chords are connected by some arrangement of bars forming an open lattice or trellis work of some kind. These have enjoved a great popularity for bridges of the largest size, and also for smaller ones, where the load being light it was difficult to design an economical plate girder without using a web undesirably thin for practical conditions. 
In these as in the plate web girders the fault of insufficient depth and consequently needlessly large chord sections has been very prevalent. At Cremorne on the Melbourne and Brighton Railway there is a lattice girder bridge $\mathrm{I} 40$ feet span and Io feet deep, built about fifty years ago. Some twenty years since, it was required to build a second bridge at one side of it to carry the Gippsland Railway, and, although there was a desire for the sake of appearance to keep the two structures of uniform depth, the advantage of increasing it was so great that the new bridge was made 20 feet effective depth for the same span. See Fig. 5 I.

Apart from this defect the principal faults to be found in girders of this class are-

II. Incomplete triangulation.--As stated on p. 18 requirement $c$, every framed structure should consist of a complete and continuous series of triangles, the triangle being the only polygon whose figure is fully determined when the length of its sides are fixed. Such a structure is subject to longitudinal tensions and compressions only, and is free from bending moment and shear, and so utilises most advantageously the material of which it is composed. Now in actual existing structures glaring departures from this rule are sometimes seen, as in the case of the shore girders of the old footbridge over the Yarra at the Botanical Gardens, Melbourne (Fig. 20). Here it must be obvious to anyone having the slightest knowledge of the subject that a single strut, as shown by the dotted line. would have carried the triangulation to its proper termination, and been far cheaper and in every way better than the complex and costly arrangement of plates, angles and rivets actually employed. As this structure is now disused, its defects have no further interest. In future structures they should, however, be avoided.

12. As an error in the opposite direction to the last redundancy may be next quoted.-This fault is very widespread, and has received a good deal of defence from influential quarters. But such defence has usually been more in the direction of palliation than justification. Redundancy may be defined as a duplicate system of triangulation connecting identical points. In such a case the stresses in the bars become indeterminable by statical calculation, and can be computed only 
by a much more complex and less satisfactory method based upon the elastic deformations of the various parts, and the result is likely to be vitiated by variation in the coefficient of elasticity, and to a still more serious degree by imperfections of workmanship invisible in the completed structure. To explain more fully, a redundant structure minus certain of its bars presents a complete system of triangulation. Suppose now that the remaining bars are by accident made a little too long or too short, and are forced into their places with violence, a set of stresses of possibly great severity is induced throughout the structure which may modify profoundly the result of any calculation. Hence redundancy, while rarely, if ever, of any real advantage, may lead to most undesirable consequences. As a gigantic example of this defect, the Charing Cross Railway Bridge over the Thames at London, illustrated in "Humber's Iron Bridges," and shown in outline in Fig. $2 \mathrm{I}$, may be noted. Most text books, in dealing with this type of girder, assume that the verticals transfer half the load from the loaded to the unloaded chord, that is in the present case from the bottom to the top. The author is satisfied from a somewhat complicated investigation of elastic deformations that this is not the case, but that the verticals are alternately in tension and compression of considerable magnitude.

Minor instances of this fault are very common, and to forbid redundancy absolutely would mean condemning many otherwise meritorous designs. We may, however, I think, say first, that other things being equal or nearly so, preference should always be given to non-redundant arrangements, and second, that if for sufficient reasons redundant ones be adopted special care should be taken that they are put together in a perfectly unstressed condition. In French practice this fault is very prevalent, and a gigantic example of it is to be seen in the Eiffel Tower, a structure which, like the Charing Cross Bridge, would undoubtedly be much improved by the removal of numerous costly parts.

13. Curvature of members.-Considering that every part of a properly designed framed structure is a simple strut or tie subject to longitudinal stress only, the necessity of absolute straightness is an immediate consequence. Strange to say, how- 
ever, owing to some peculiar warp of the human mind, many persons persist on fanciful grounds in increasing the cost and diminishing the strength of structures by the introduction of curved members. A curious example of this is to be seen in the evolution of the frame of the modern bicycle. For years this vital part was made of ridiculous shapes presenting complex curves utterly contrary to scientific principles, and the result was, despite the most liberal employment of material, straining, weakness, and frequent fracture. The modern diamond frame, every part of which is perfectly straight, is thoroughly scientific, and, with half the material of the earlier frames, is far more rigid and absolutely free from fracture under ordinary and reasonable use. The front panel of the bicycle frame is apparently opposed to condition (c) p. I8, not being a triangle. It can be shown, however, that if its top and bottom bar converge to a point vertically over the front axle, it becomes a virtual triangle, and does not tend to deform under the weight of the rider.

Perhaps the most extraordinary and inexcusable instance of this fault in modern times is to be seen in the huge and costly Jubilee Bridge over the Hoogly in India, described and discussed in the "Proceedings of the Institution of Civil Engineers,"' Vol. XCII., ı 888, an outline of the terminal panels of which is given in Fig. 22. Here one of two things ought to have been done, either $\mathrm{AB}$ should have been made perfectly straight, or the space $\mathrm{C}$ should be plated over, the latter being the only practicable remedy now. This grave fault was animadverted upon by myself in the "Engineer" of 5th June, I 885 , and afterward by Professor Max am Ende before the Institution of Civil Engineers, London. A second and still more recent example is seen in the Warburton Bridge over the Manchester Ship canal, illustrated in "Engineering " of 26 th January, 1894.

But while condemning as strongly as possible such designs as the Jubilee and Warburton Bridges, I would make an exception in favour of many bowstring and hogback girders such as the new Cremorne Bridge on the Gippsland Railway near Melbourne, Fig. 5r. Here the top chord forms a bold and graceful curve, very pleasing to the eye, but the panel points where the web members come in are so numrous that the curvature in each 
panel or length of the chord is imperceptible. If the chord was made polygonal, each panel being straight, its outline would not differ visibly from what it is at present. A chord curved at a large radius and divided into panels so short as to be practically straight, cannot be reasonably objected to.

14. Eccentricity. - The condition laid down on page 18 that a properly designed framed structure should consist of a series of triangles having common angles, involves the necessity of any three or more bars meeting at a point being so arranged that all their mean fibres pass accurately through that point, the mean fibre being defined as the line passing through the centre of gravity of the cross section of each bar. If these mean fibres or gravity lines, as they are sometimes called, do not meet truly, bending moments and shears are set up in the bars, and loss of strength ensues, unless obviated by the introduction of additional material. Very great laxity is sometimes shown in this respect, as may be seen from Fig. 23, representing portion of a large girder erected over Primrose Street, in connection with the enlargement of the Liverpool Street Railway Station, London, illustrated in the "Engineer," of 2 ist August, 1896. Here it is to be noted that the end pillar, instead of being placed centrally over the rocker support, is placed most eccentrically so as to concentrate the stress on one edge instead of distributing it equally, and, further, that the mean fibres of the last diagonal and end pillar meet far above the upper surface of the top chord, instead of as they ought in its mean fibre. Another glaring case is shown in Fig. 24, representing part of a bridge near Windsor, N.S.W., inspected some years ago by the writer. Recent Australian practice appears fairly free from these inexcusable faults, which is more than can be said for English practice.

A most disastrous accident took place ten years ago near Boston, U.S.A., causing the destruction of a train, the loss of twenty-five lives, and injury to about one hundred persons. This all started from the failure of the improperly designed bridge hanger shown in Fig. 25. This hanger had ample sectional area for the direct pull, but that pull was imposed so eccentrically as to give rise to a bending moment which increased the stress several times. This and other cases show the necessity 

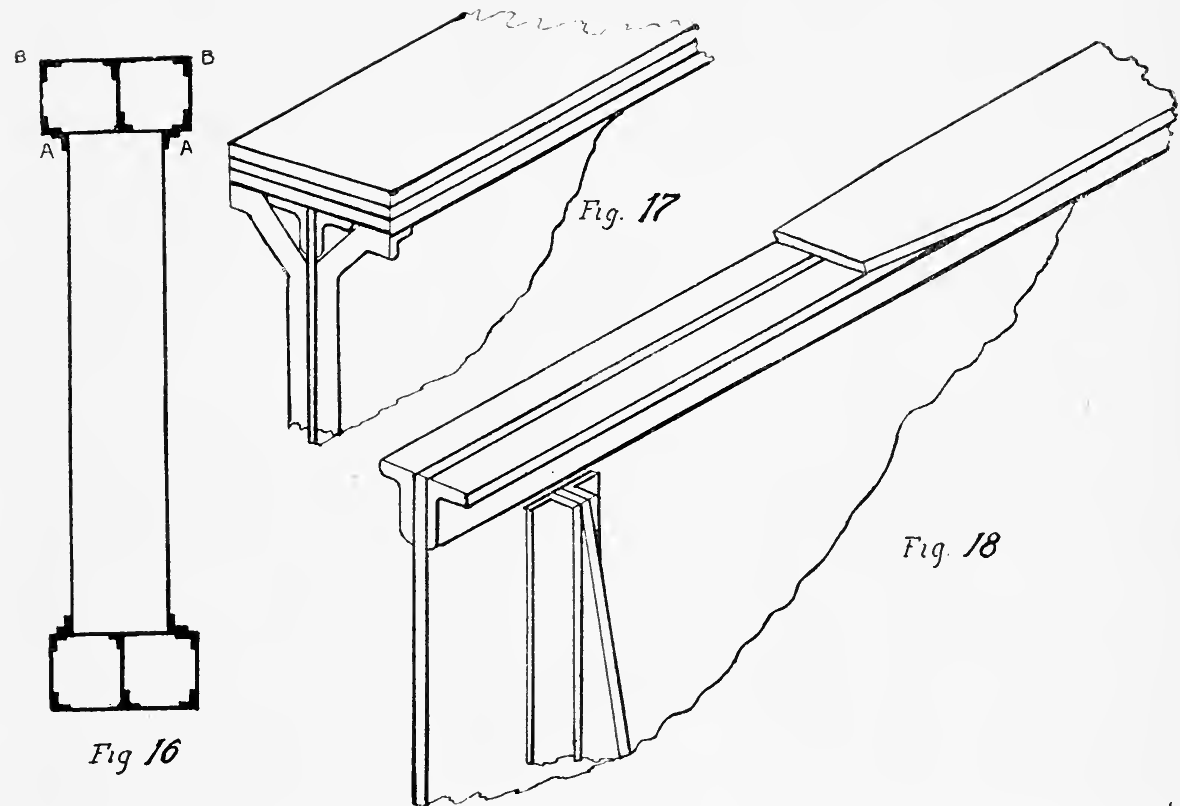

Fig 16

م 0 D 20
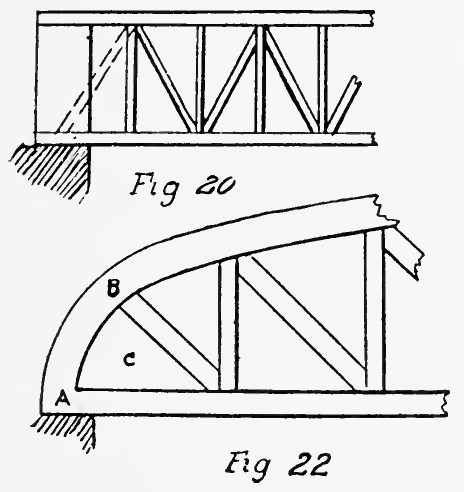
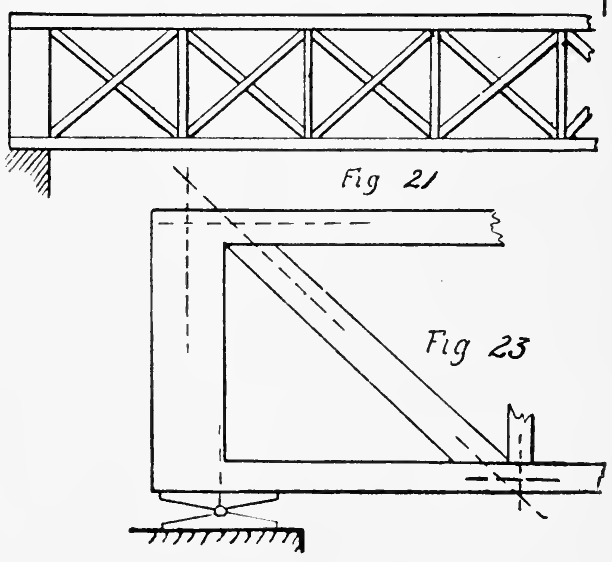
Un: 
of guarding most carefully against this fault. Few persons realise that in a rectangular section a deviation of the centre of stress from the centre of figure by one-sixth of the width of the bar, doubles the stress on one side and reduces that on the other to zero.

Eccentricity should be most carefully avoided in designing new structures, and when it exists in old ones, special local strengthening should be applied, unless computation shows the parts to contain a sufficient excess of material to resist the moments and shears involved as well as the direct stresses.

15. Unscientific and wasteful end pillars.-There are multitudes of girders in existence which are reasonably and consistently designed as far as chords and web members are concerned, but which have the terminal verticals of excessive size and most complicated construction, involving great and altogether unnecessary increase in the weight and cost of the girder. No defence or excuse for this anomaly has ever reached the writer's ears, but its vitality is remarkable, as it appears not only on bridges built thirty or forty years ago, but even in quite recent structures, including some of those crossing the Manchester Ship Canal. One example is shown in Fig. 20, where the end pillar or box contains at least three times as much material as would be needed for a proper terminal diagonal or "batter brace," to use the American term. A second example is shown in Fig. 26, representing part of a bridge over the Rio Verde, South America. Here the end pillar $\mathrm{AB}$ has 98 square inches sectional area against $2 \mathrm{I}$ square inches in the adjoining diagonal $\mathrm{BC}$, which bears 40 per cent. more stress, and 20 square inches in the vertical $\mathrm{CD}$, which endures a compression three-fourths of that on $\mathrm{AB}$. Were $\mathrm{AB}$ reduced to 25 square inches area, which would be most abundant, I I per cent. of the weight and cost of the whole girder would have been saved. There is, however, a still better arrangement originated by Whipple, an American Engineer, and used in America for nearly half a century past. It is to abolish the bars $\mathrm{AB}, \mathrm{BC}, \mathrm{BD}$, and insert a compression diagonal $\mathrm{AD}$ as shown by dotted lines. This will leave the compression on the top chord unchanged, and the stress on all except the end panel of the bottom chord, which at present is unstressed, 
though of massive section, and will reduce the stress on CD largely, thus saving no less than 17 per cent. of the weight of the girder. The remarkable economy due to replacing the clumsy end vertical by a sloping compression piece or "batter brace" of theoretical section is now somewhat tardily being recognised by English Engineers It has been universal practice in America since the time of Whipple.

This is an error to be avoided in future designs. In existing bridges it simply means waste of money, but does no further harm.

I6. Unduly numerous systems of triangulation.-This is a very common fault of the lattice girders of 40 or 50 years ago. A multiplicity of small bars, many of which for practical reasons have to be much larger than calculation requires, which involve a large amount of complicated workmanship and often are not placed in proper relation to the points of attachment of the cross girders, constitutes a usual characteristic of early practice. Modern work, however, usually avoids this fault, and as it in most cases where it exists means waste and not weakness, it is not. a matter needing any present action.

I7. Inefficient forms of compression nember.-In consequence of the high compressive resistance of iron or steel the transverse dimensions of compression parts of girders have to be comparatively small relatively to their length, consequently the tendency is to fail by buckling or long column action, rather than by direct crushing, and the strength attained depends largely on the success with which this tendency is combated. When the column is so short as to fail by true crushing, the form of section is immaterial, provided only the required area is present, but when it is longer the form of section has a most profound influence on the resistance. The best form is that which presents the greatest resistance to bending laterally, either of the column as a whole or of any constituent part. Hence a good compression member must approach in form to an efficient beam, but as it may bend in any plane and not in one only, it must be an efficient beam in every direction. The ideal long column is a hollow cylinder which is a fairly and equally good beam in every direction. The greater the diameter the greater the resistance to bending as a whole, but there is a limit to 
desirable increase of diameter and consequent reduction of thickness owing to the tendency of very thin tubes to give way by wrinkling or corrugation of the thin metal. Fig. 27 shows full size a sample of bicycle tube that has been crushed in the University testing machine, its original dimensions being shown by dotted lines-the metal is .035 thick and the ultimate load $4400 \mathrm{lbs}$. Unfortunately the circular tube is very unsuitable for the convenient attachment of other parts, and consequently has been generally rejected by the designers of framed structures, although the great Forth Bridge and the modern bicycle frame are instances to the contrary. A further reason for rejecting the circular tube is, in structures of ordinary size, the inaccessibility of the interior for purposes of inspection, cleaning, painting, and repair. To describe and discuss all the sections that have used for compression members for chord and web purposes would extend this treatise far beyond permissible limits. It must therefore suffice to enunciate general conditions to be complied with, and point out instances of conspicuous transgression of these conditions.

(a) A good compression section should have a large radius of gyration in every direction.

(b) If the column is prevented from bending in one plane by the attachment of other parts, and is not so prevented, or not so effectively prevented from bending in a plane at right angles to the first, it should, if its radius of gyration varies, be placed with its maximum radius of gyration in the second plane.

(c) Thin unsupported edges should be avoided, or, if unavoidable, should not be counted as part of the effective section, as they are very liable to buckle.

(d) Flat surfaces should not be made too thin in proportion to their width. A proportion of $I$ to 30 is quite small enough. If this be passed the central part of the flat face becomes of little value for resisting compression.

(e) If two compression members be connected togetner with the object of preventing their bending in the plane of the connecting pieces, those pieces should be arranged so as to constitute an efficient web 
system, forming with the two compression pieces a complete girder designed for resisting bending.

(f) The resultant force should pass exactly through the centre of gravity of the cross section.

We now proceed to cite cases of infraction of these rules, with consequent loss of strength.

Fig. 28 represents one girder of a small over bridge at the Spencer Street Railway Station, Melbourne. It is 45 feet span and about 4 feet deep, and consists of twelve panels. All the diagonal web members are of $3 \times \frac{3}{8}$ inch iron. These are suitable enough for tension purposes, but most inefficient in compression, having a radius of gyration across the plane of the girder of only .I inch or about I-30oth of the length. This unfortunate girder further presents the faults of redundancy, owing to the presence of unnecessary verticals, and of absurdly heavy and complicated end pillars.

Fig. 29 represents an amended design in which the compression diagonals are made of angle iron having a radius of gyration many times greater than that of the flat bars, and in which the faults of redundancy and disproportionate ends are avoided.

Inch to the foot models in iron of each of these girders were constructed at the University and tested to destruction, with the following results:-The amended design contained i 6 per cent. less iron than the original owing to the omission of the massive end plates and intermediate verticals. It involved much less workmanship owing to there being less than one-third the number of rivets, and the time taken in making it was less than half that of the other. Its actual breaking load distributed along the bottom chord as in the actual bridge was $77 \mathrm{rlbs}$. as against 208 for the original structure. Thus with identical external dimensions, and very little change in appearance, the cost of the structure was largely reduced, and its strength increased nearly fourfold. The mode of fracture of this defective design was, as was predicted by calculation, the buckling or side ways bending of the weak compression diagonals near the end. There would be no difficulty and but little expense in increasing the strength of this structure threefold by simply clamping angle irons to the most heavily stressed compression 

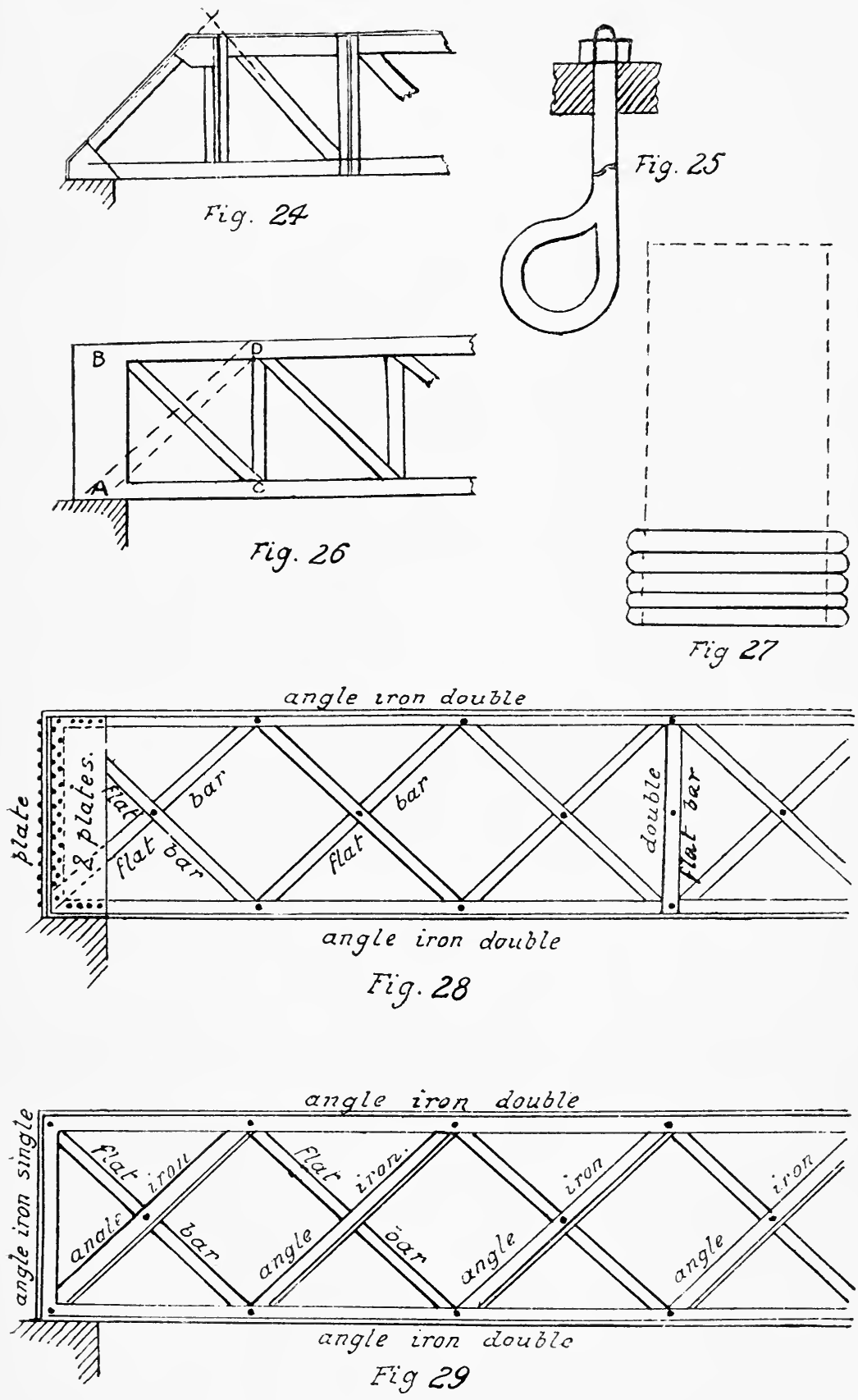
Butate.

Jif

IFCUNin 
diagonals so as to prevent their bending, and this ought to be done, and was long ago urged by the writer, but without result.

Fig. 30 represents the section of a large buttress or inclined strut, erected at great cost on the down stream side of the Victoria Street Bridge, near Melbourne, for the purpose of remedying an entirely imaginary lack of lateral stability. Its radius of gyration is 3.9 inches in the plane of its web, and $I$ inch at right angles to that plane. It is 25 feet long, and is regarded as fixed in direction at the ends, though whether this fixing is perfectly reliable is not altogether certain. It is braced against lateral bending by a costly system of bars in the plane of the web. Taking the most favourable view, calculation shows that it would give way under a compression of 98,000 lbs., whereas if it were turned the other way, as it easily might have been, so as to be braced in the direction in which it was weakest, its resistance would be more than $200,000 \mathrm{lbs}$. This is an instructive example of the neglect of condition $b$, p. $3 \mathrm{r}$.

Fig. $3^{I}$ represents a very usual section of compression chord of the earlier types of lattice girder bridges in England and Australia. Here the side plates are so thin and so liable to buckle or wrinkle at the edges that it was decided in the calculations made by Professor Warren and the writer, and published in the Report of the Royal Commission on Railway Bridges, N.S.W., I886, to ignore the outer half of their width as contributing anything to the compressive resistance of the chord. As an example of improved practice, Fig. 32 is given, representing the upper chord of the very fine steel bridge over the Yarra, on the Gippsland Railway, Fig. 5 I.

Of transgression against condition $d$, I am happily unable to quote a case.

Condition $e$ applies to very numerous cases of compression diagonals, where two parallel angle, $\mathbf{T}$ or channel bars are braced together. Fig. 33 represents an arrangement that has been adopted on the two most recently erected bridges over the Yarra, and shows that the latest practice is not always the best. The only function that the cross connections perform is to ensure that the two main bars bend the same way, and if they are of themselves inclined to do so no gain of strength ensues as compared with entirely disconnected bars. Fig. 34 shows a 
vast improvement with the same amount of iron and riveting, and the dotted lines show how any lateral bending must be of a very different character to that of Fig. 33. In fact, the shorter curves and more numerous nodes in the latter case are equivalent to a reduction to the effective length of the column to the distance $\mathrm{XY}$, which means a valuable gain in strength. There would be no difficulty and but little expense in altering these structures now, removing the cross pieces one or two at a time when the bridge was free from live load, and replacing them by square plates as in Fig. 34. An even better but slightly more expensive arrangement would be to insert a complete triangulation similar to that shown in Fig. $3^{6}$.

Fig. 35 represents a type of braced strut appearing in the late Sir John Hawkshaw's great railway bridge over the Thames at Charing Cross, Fig. $2 \mathrm{I}$, and copied thence extensively in Europe and in New South Wales. It requires but little consideration to detect the weakness of this arrangement. Suppose there is a tendency for the member to bend to one side, the rectangular panels will become rhomboidal, one diagonal being extended, and the other reduced in length. Now if these diagonals are straight they will oppose the maximum resistance to such distortion, but if bent or crooked, as in the Charing Cross Bridge, the extended one will tend to straighten, and the compressed one to become more crooked. Experiments have been made at the University on different types of compression members, and have shown that great advantage ensues from replacing this unsatisfactory double system of crooked flat bars, by a single diagonal system of straight bars, as shown in Fig. 36. This improvement might easily be applied to actual structures, taking advantage of times when they are free from live load to remove the one and insert the other.

Fig. 37 is a photograph of a number of experimental compression pieces tested at the University, arranged in order of merit. The best of these carried, in proportion to the metal it contained, rather more than twice the load that the worst did. These specimens were free to bend in their own plane, but braced at three points in a direction at right angles to their own plane, and represented compression diagonals in closely latticed girders intersected and kept from bending in the plane 


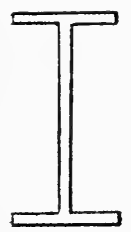

Fig. 30

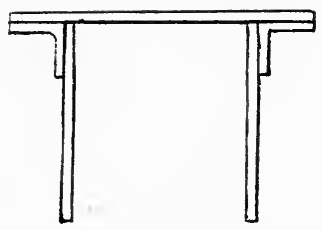

Fig. 31

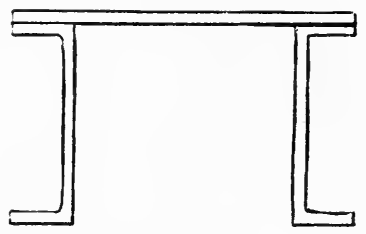

Fig 32

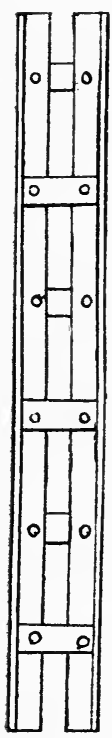

Fig 33

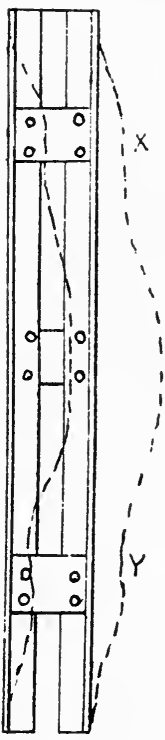

Fig. 34

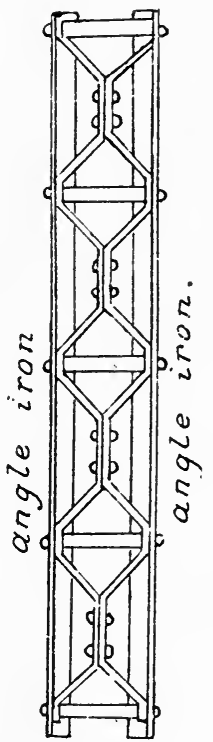

Fig. 35

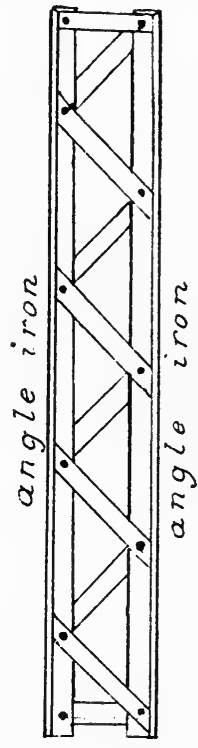

Fig 36 
c 


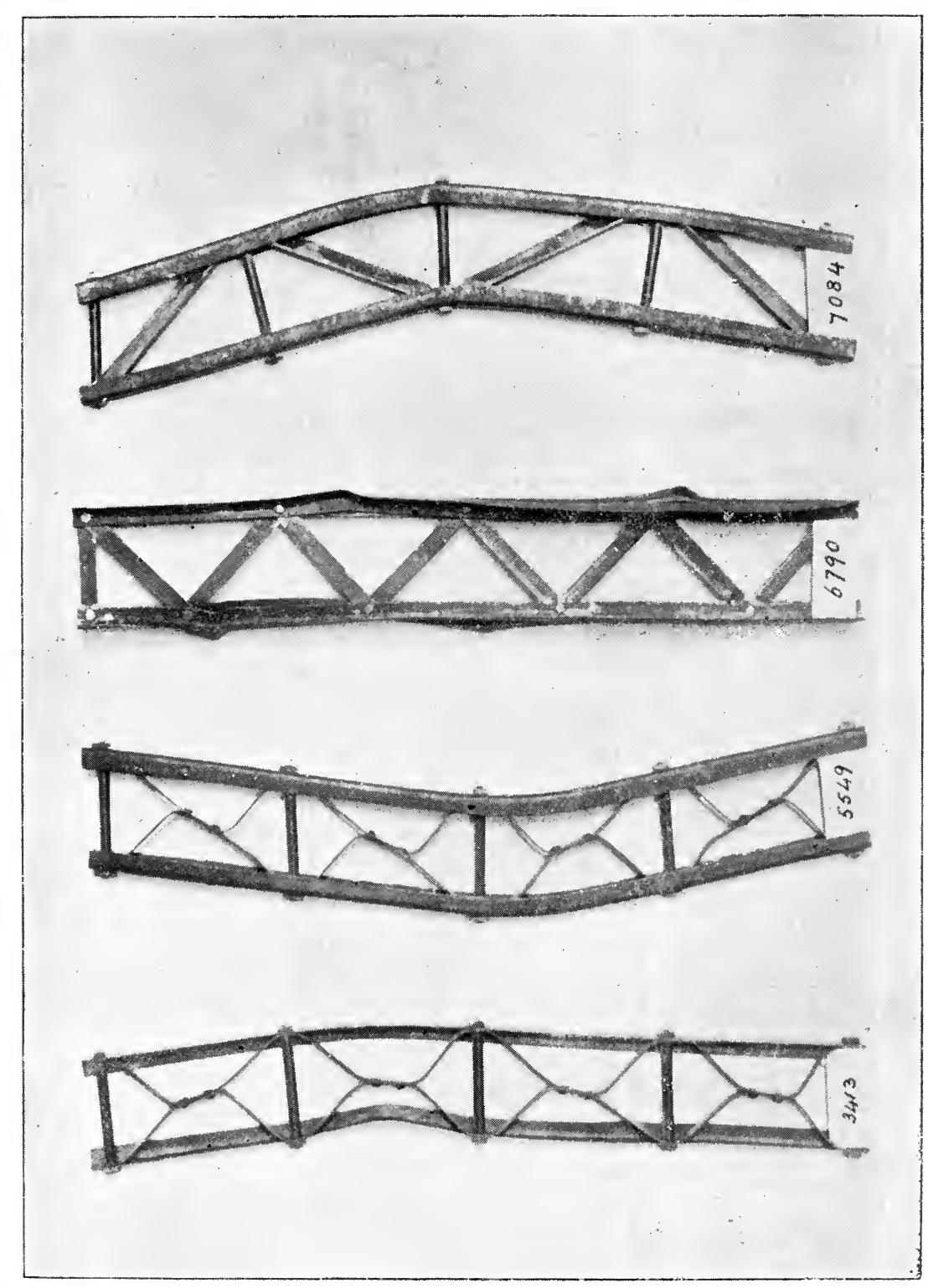




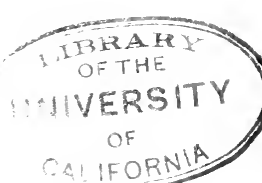


of the main girder by the tension diagonals. The figures at the bottom indicate the ratio of the load carried to the weight of the structure, and thus express the relative values of the various systems. The first and third of these models have angle bars and the second and fourth channel bars for their sides.

A striking series of experiments illustrating the importance of condition $f$ is given in Professor Warren's “Engineering Construction," p. I95, on square columns, three sides of which are plate, while the fourth is an open lattice work, incapable of resisting compression. These columns rested on turned pins, as is usual in American bridge work. In two cases the axis of the pin bisected the square being parallel to the latticed side, an arrangement that probably many designers would adopt without a second thought as obvious and natural. In other two the axis of the pin passed exactly through the centre of gravity of the three resistant sides, and was distant from its previous position by one-fifth of the side of the square. The length of the columns was 20 feet, the side of the square 8 inches, and the columns resting on pins passing through their centre of gravity proved on being tested 65 per cent. stronger than the others.

18. Lack of provision to resist the effect of unsymmetrical loads.--Some of the older lattice bridges show this defect. They are designed merely for loads symmetrically arranged about the centre, and, should the girder be loaded from one end to the centre only, considerable compressions will be thrown on thin flat diagonals properly fitted to bear tension only. Should these diagonals buckle, the girder can be saved from collapse only by the resistance to bending of the top and bottom chords. In any ordinary lattice, $X$ or $N$ girder there are a number of diagonals near the centre of the span that are double acting, that is, have to act both in compression and in tension as the live load changes its position. These should always be of $T$, angle, channel, girder or other stiff sectionmere flat ribands are inadmissible. This defect may easily be remedied by riveting a light angle iron to one side of the flat band.

In two Whipple trusses of considerable size near Melbourne, instead of making the central diagonals stiff, so as to act in 
compression if required, a light counterbrace of flat iron has been placed as the other diagonal of the rectangular panel. In every case these counterbraces have become slack on the girder being loaded. The reason is that three sides of the panel being in compression, and only one, the bottom, in tension, and further the main diagonal lengthening elastically, there are four actions at work to shorten the diagonal occupied by the counterbrace, and only one to lengthen it. Hence the counterbrace, even if most carefully fitted while the girder is on the blocks, becomes loose and flabby as in the analogous case of trestle piers in page $\mathbf{I} \mathbf{I}$. Here as there an adjusting device is most desirable and should be supplied.

19. Imperfect jointing of tension members.-The form of section and ratio of length to transverse dimension of a tension member are immaterial as regards strength, and so may be arranged according to convenience. The joints, however, are the points of vital consequence, and malformation of these often leads to serious loss of strength and efficiency. Of these joints there are two principal classes, riveted joints and eyebar and pin joints. The first of these is most usual in European, and the second in American bridge work.

In riveted work, the metal is used as it comes from the rolling mill and the attempt to utilise the full section for strength is not made. A riveted joint, in other words, never claims perfect efficiency, but is always subject to some percentage of loss as compared with the pieces connected. To minimise this percentage of loss is the object in arranging the joint, and it is possible to reduce this to the proportion of area cut away by one rivet hole. Fig. $3^{8}$ shows a properly riveted joint, which should fracture at the line $\mathrm{AB}$, passing through the leading rivet and giving an efficiency less than unity by the fraction represented by the diameter of one rivet hole divided by the width of the bar. It will not fracture through the following pair of rivet holes, because the tension is too much reduced by the action of the first rivet to permit it, nor through the third row for a similar reason. All this has been verified by careful experiments at the Melbourne University and elsewhere. In contrast with this, Fig. 39 shows a tension member weakened by no less than three rivet holes in one leading row, and many 
similar cases might be quoted. There are many more complicated forms of tension joint met with in girder work-to discuss which would occupy too much space here. Suffice it to say that the same general principles apply as in the simple cases.

The leading rivet ought to be placed in the mean fibre of the bar, which in an ordinary rectangular section is the middle of the width and the other rivets arranged symmetrically behind. Sometimes it is convenient to place the leading rivet near one side, and, as far as the writer's experiments go, the loss of strength due to such an unsymmetrical arrangement does not seem to be serious. Still it is a departure from what is obviously the right treatment, and is therefore not to be encouraged.

In arranging riveted joints it is recommended that there should be a width of solid metal at least equal to $\mathrm{I} \frac{1}{2}$ diameters of a rivet between each rivet hole and its neighbour or between a rivet hole and the edge or end of the plate, for drilled work, and $\mathrm{I} \frac{3}{4}$ for punched work, that the shearing area of the rivets be 20 per cent. in excess of the tearing area of the plate, and that the aggregate diametrical bearing area or sum of the products of the diameters of all the rivets piercing a given plate into the thickness of such plate shall be not less than half the tearing area of that plate.

If a weak riveted joint be discovered in an existing structure, and it is not possible to increase the number of the rivets, an improvement may often be made by removing the rivets one or two at a time, carefully enlarging the holes with a suitable cutting tool, and inserting larger rivets. This may be done very advantageously in punched work, for the metal removed is that which was damaged in the process of punching, and therefore of little value.

In eyebars the attempt is usually made to secure perfect efficiency, in other words, to make the joint as strong as the bar, and when the bar is very long this is a great economical advantage, as the whole of the material is then utilised fully. In order to do this the proportions of the eye must be carefully attended to. These have been determined experimentally by Brunel, Sir Charles Fox, and Berkley in England, and Shaler Smith and others in America, and their conclusions may be 
generally summed up as follows, averaging the results when the authorities differ, as they do, to a small extent.

(a) The internal diameter of the eye or diameter of the pin must never be less than two-thirds of the width of the bar, and if the bar has a thickness of more than one-fifth its width this should be progressively increased, till, when the thickness is half the width, this diameter is I.2, and when equal, the bar having a square section, I.9 times the width.

(b) The sectional area of the metal on both sides of the eye should be $\mathrm{I} .33$ that of the body of the bar for bars whose thickness does not exceed one-fifth of the width, increasing to 1.76 when the thickness equals the width and the bar becomes square. The outline of the bar must consist of easy curves, and sharp re-entering angles must be most carefully avoided. (See Fig. 43.)

(c) The pins must be designed as beams to endure the bending moment due to the pull of the eyebars, and if this necessitates a larger diameter than the previous rule $(a)$ gives, the eyes must be correspondingly enlarged.

In America the eyebar construction in its most perfect form is almost universal in the tension parts of the larger bridges, and a very magnificent example of recent American practice is to be seen in the great Hawkesbury Bridge, N.S.W.

In Europe, India and Australia it is less usual, and where it exists is often of very defective design, as the following examples will show.

Fig. 40 represents the wind bracing of the piers of the illfated Tay Bridge, which was destroyed by a gale in 1879, involving the destruction of a whole railway train and every person upon it. Here no attempt has been made to form a proper eve, and only about half of the strength of the bar is really utilised.

Fig. 4I represents a tension eyebar from the Taptee Viaduct, Bombay, Baroda, and Central India Railway, of which the Gundagai Bridge, N.S.W., appears to be a copy. It is also very inefficient. 
Fig. 42 represents the eyebar diagonals of the great Moorabool Viaduct on the Geelong and Ballarat Railway. The most cursory inspection will reveal how far this departs from orthodox proportions with its diminutive pin, its sharp internal angle at $\mathrm{A}$ leading to great local intensification of stress and its two sides in the aggregate barely equal to the body of the bar instead of being 33 per cent. greater. Experiments were made at the University on models, first in lead, then in brass, and finally in iron on a quarter full size scale, to determine the eifficiency of this joint, and the results varied from 64 to 70 per cent. Further experiments by the Victorian Railways Department led to a practically identical conclusion Considering that there are several hundreds of these bars in the structure it does seem strange that this defective form was decided upon without experiment, and also that the example of Brunel and others who had used fairly good eyebars in suspension bridges years earlier was disregarded. After some years of discussion the Railway authorities vielded to the writers representations, and condemned this viaduct as a double line bridge. It now carries a sing.e line only, though containing abundant material if rightly disposed to make an amply strong double line structure.

In the bottom chord of this viaduct eyebars are also used, having the extraordinary peculiarity of the centre of the eye being an inch above the centre line of the bar. As, however, this chord is of excessive sectional area no real danger arises from this singular departure from correct practice.

Structures having defective eyebars in them can be improved only by reconstruction and replacement of the weak parts. If this is impossible, the load carried should be reduced, by narrowing the deck if a public road is carried or removing a line of rails, placing the remaining line centrally as was done at the Moorabool Viaduct.

Fig. 43 represents an eve from the Hawkesbury Bridge, and may be regarded as an example of the best and latest practice.

The joints of compression parts are not often a source of weakness. If they are solidly butted together, the only need for riveting is to prevent lateral dispiacement. The usual practice, however, is to assume that the ends are not in contact, 
and insert sufficient rivets to carry the whole stress as in tension joints. In this case there is no need to have the single leading rivet, and the arrangement shown in Fig. 39 is admissible. Should the rivets of a compression joint be insufficient to take the stress they will distort slightly and permit the ends of the plates to come into contact, when further yielding will be effectually prevented. The practice has sometimes been adopted and appears reasonable, of putting the girders together with but a few loosely fitting "service bolts" in the rivet holes of the compression joints, then loading them with a weight sufficient to bring the ends of the parts into perfect contact, and then riveting up. If this method be adopted the number of rivets in compression joints may be made very small.

20. Local weakness at intersection of web members. - In the older form of lattice girders the web diagonals near the centre of the span are usually made of angle bars, which give a suitable section in view of the circumstance that with varying conditions of loading they may be cal'ed upon to endure either compression or tension. When two of these angle bars intersect it is a usual practice to cut away one limb of one of them, reducing it to a simple flat bar, which is further reduced by the hole needed to receive the connecting rivet. Thus the remaining or net sectional area becomes about one-third of the gross area, and as it further is subjected to the most injurious kind of stress, that alternating from compression to tension, during the passage of the load, a very serious but easily overlooked weakness ensues. Fortunately the remedy is simple and cheap. It consists in adding a second layer or reinforcing plate to the diagonal at the weak point, extending about a foot on each side of the intersection, and connected with the unmutilated part of the angle bar with a sufficient number of rivets.

21. Arrangements involving serious secondary stress.

The stress upon any bar of a framed structure with rigid joints is of two kinds, primary and secondary. The primary stress is that computed by the ordinary methods of analytical or graphic statics; in other words, by the successive application of the proposition known as the parallogram or triangle of forces. This investigation, provided the structure is not redundant, is simple, and the result certain, admitting no pos- 
sibility of dispute. All such calculation, however, is based on the assumption that each set of bars meeting at a point is connected by a perfectly frictionless hinge joint. This assumption is by no means strictly true, even in eyebar work, on account of friction, while in structures having the joints made by complicated groups of rivets it is manifestly highly erroneous. What then is the nature and magnitude of the extra, or, as they are now called, secondary stresses, due to the friction or rigidity of joints, and how may they be minimised?

This question was first discussed by the Austrian investigator, Manderla, in 1878 , but owing to the intricacy of the calculations, and the delicate nature of the experiments needed, we have so far arrived at but approximate determinations of its value.

The completest treatment that the writer has met with is that of Professor W. Ritter, of the Polvtechnic School of Zurich, and was published in 1884 .

Manderla's work is referred to in Bender's "Economy of Design of Metallic Bridges," New York, 1885. Bender states that he has applied Manderla's method to a number of examples, and that he has found in a " 100 foot Whipple truss, 20 feet deep, a maximum secondary strain of 8 per cent." in the centre of the top chord. He also says that he has found "Secondary strains of $\mathbf{1} 72$ per cent." of the primary stresses in a triangular pin-jointed girder of $1 \mathbf{I} 8$ feet span and $\mathbf{I 2 . 5}$ feet deep in South Germany. Again he speaks of "secondary strains as high as 180 per cent." over the middle piers of continuous bridges. Now, all this is most unsatisfactory and alarming. Unsatisfactory, because Bender gives no drawings or detailed dimensions of his bridges, nor does he show how he arrives at his results. Alarming because the only meaning that can be attached to his words is that the secondary stresses in structures of ordinary type may be greater than, in fact, nearly double of the primary stresses, and if this be the case, the structures affected must be most imminently dangerous, indeed it is difficult to understand why they have not long since fallen.

Ritter's work, as quoted by Koechlin in his "Applications de la Statique Graphique," Paris, I889, is much fuller and 
more satisfactory, and his results more intelligible and less alarming. The maximum secondary stress that he arrives at in structures of ordinary proportions, is less than 30 per cent. of the primary stress. Still, his method appears to the writer to be too general, and to fail in indicating exactly at what points of a frame the severest stress is to be expected. The writer has, after much consideration, arrived at a method, which he submits as giving, without inordinate labour, a fair approximation to the secondary stress in, at any rate, the simpler types of structure. It consists of the following operations:-

(a) From the primary stress and sectional area of each bar, and its known modulus of elasticity, its change in length is computed. This will be an elongation or shortening, according as the primary stress is tensile or compressive.

(b) This change in length is exaggerated a convenient number of times. The writer increases it one hundred fold.

(c) The frame is then re-plotted with the altered lengths of the bars. One result of this is that the panel points of the top and bottom chords, instead of lying in straight lines, will lie in curves, which in most cases are approximately circular, but in others that have been tried, have a cusp at the centre, like a Gothic arch inverted. The cusp indicates a point of intense secondary stress.

(d) A smooth and regular curve (usually circular) is drawn through all these panel points, and at each panel point a tangent to this curve is drawn. This is most conveniently done by taking a well-tempered piece of spring steel and bending it so as to pass through all the points.

(c) Lines are drawn, making the same angles with these tangents that the diagonals or web members made with the chords, when the structure was free from stress. If two such lines drawn from the two extremities of a diagonal or web member coincide, forming one straight line, that web member is free from secondary stress. But if, as is usually the 
case, they do not coincide, then the diagonal, which, by virtue of its rigid attachment to the chord is tangential to these lines at its ends, must be bent into a curve, usually of double curvature, or $\mathbf{S}$ curve as it is often cal'ed. This curve will present a point of contraflexure and consequently of no bending moment at or near the mid-length of the bar and each part of the bar will be a cantilever, the deflection of the end of which can be measured on the exaggerated scale adopted, and from this, its width, and the modulus of elasticity, the secondary stress can be computed. This secondary stress is usually least at the centre of the bar, increasing to a maximum at the ends. To find the exact curve assumed the piece of spring steel mentioned before may be applied.

$(f)$ The secondary stress of the chords is computed from the radius of the curve $d$ and in most cases is approximately uniform throughout.

To carry out this method, diagrams of one of the simplest of which Fig. 44 is a greatly reduced copy, have been made, and from them the following results have been obtained:-

The smallest secondary stress so far as he has gone, the writer has found in the simple Warren girder, consisting of one series of equilateral triangles.

In this girder, assuming that the transverse dimensions of the chords and web members to be equal, and their sections symmetrical about the neutral axis, the secondary stress in the web members is about four times that in the chords.

Taking a Warren girder of 8 panels as shown in Fig. 44, of roo feet span, with all members $\mathrm{r}$ foot wide, stressed to 6 tons per square inch with ordinary provision for partial loading, and a modulus of elasticity of $26,000,000$, the secondary stress in the chords was 8 per cent. of the primary, and in the web members 30 per cent. of the primary. Any reduction in the width of any bar (as measured in the plane of the frame) without altering its sectional area, reduces the secondary stress in the same proportion. Hence it is desirable to keep the web members of girders as narrow as other considerations will permit. 
The usual trough or $T$ section employed for chords is subject to only about half of the increase of stress, that a rectangular or other section symmetrical above and below experiences. This is due to the fact that the neutral axis lies so much closer to the side where the primary and secondary stresses are additive.

The $\mathbf{N}$ girder or that with alternate vertical and diagonal web members is subject to considerably more secondary stress than the Warren of equal dimensions and width of bars, especia.ly in the vertical members. It also shows an intensification of secondary stress at the midspan if made with an even number of panels. At each of these points the secondary stress is at least $5^{\circ}$ per cent. greater than at the corresponding points of the Warren girder.

In the $X$ girder, Fig. 29, the distribution of secondary stress is peculiarly complicated. That in the chords is variable, attaining maxima values at alternate panel points, and vanishing, or nearly so, at the other alternate panel points, its maximum value being about double what it is on the corresponding Warren girder. That in the diagonals is about equal to what exists in the Warren girder if the diagonals are not connected at the points of intersection. If they are it is increased about 50 per cent.

At the root of a cantilever or over an intermediate support in a continuous girder, the secondary stresses, both in chords and web members, attain a value nearly twice as great as those in a girder simply supported at the ends and designed to carry distributed moving loads, such as ordinary road and railway bridges are subjected to.

The foregoing results, while very far removed from the alarming statements of Bender, nevertheless err on the side of pessimism. The subjoined tacts all indicate certain sources of relief from secondary stress, which neither Ritter's nor the author's methods of investigation take account of.

I. The full stress of 5 or 6 tons per square inch is not maintained throughout any structure. Many parts are, for convenience, to obviate the use of too many different sections of metal, or to facilitate jointing, made 10, 20 , or even sometimes 50 per 
cent. more massive than calculation requires. Hence the deformation of the structure is reduced below what it would be if more closely designed. This tends to reduce secondary stress.

2. In both Ritter's and the author's methods it is assumed that the chord sections are so much more massive than those of the web members as to completely overpower them, and compel them to accommodate their direction to that of the chords. This is by no means absolutely true. Assuming as a fair average that the web members are one-fourth as stiff as the chords, there will be a rotation of the joints, tending to reduce the secondary stresses in the web members by 25 per cent. and increase those in the chords. As the previously determined secondary stress in the web members was, other things being equal, about four times that in the chords, this means a distinct gain.

3. By virtue of resistance to secondary stress and entirely apart from primary stress, a certain small portion of the load is carried.

4. It is doubtful if even the tightest riveted joints are absolutely rigid, and any microscopic yielding or adaptation in them tends to reduce secondary stress.

In order to provide for secondary as well as primary stress, with economy it is recommended in new design

(a) That other things being equal or nearly so, preference be given to the Warren or equilateral type of girder, with a single system of triangulation.

(b) That chords of trough or $\mathrm{T}$ section be preferred to those that are symmetrical about their horizontal neutral axis.

(c) That all members be kept as narrow in the plane of the girder as other conditions permit.

(d) That the unit stresses in the web system be made about ro per cent. less than those adopted in the chords.

(e) That girders of ample depth, say not less than $\frac{1}{10}$ of the span, be preferred to shallower ones. 
(f) That those portions of continuous girders immediately above non-terminal supports be made about 15 per cent. more massive than the corresponding parts of ordinary girders. This extra strength to taper away till it disappears at the point of contraflexure.

Existing bridges should have their stresses determined by the method previously described, and where the secondary stress and primary stress together exceed the usually permitted primary stress by more than $3 \circ$ per cent., either the load should be reduced or the weak part strengthened. This strengthening must be made without increasing the breadth of the bar.

Girders of the $\mathbf{N}$ type with broad web members, such as that shown in Fig. 23, where the diagonals have a width of one-eighth of their length and are very firmly riveted, should be looked upon with the greatest suspicion and taken in hand first, also continuous girders of ail types.

As some of the above remarks may appear condemnatory of the American type of girder, of which the Hawkesbury Bridge is so magnificent an example, it is well to point out that, owing to the narrowness of the web members relatively to their length, the secondary stress is here comparatively small, not exceeding, according to the writer's method, ro per cent., even on the assumption that the joints are perfectly rigid, which, being eye-bar and pin construction, they hardly can be, no matter how tightly fitted and bolted up.

22. Arrangements involving severe temperature stresses.-The existence of heavy stresses due to variations of temperature has been generally recognised in the case of metallic arches and suspension bridges, but not in the cast of ordinary girders. There is, however, reason to believe that in a subtropical country like Australia, and especially in those parts where the air is dry, and so imposes but little resistance to the solar radiation, very serious stresses, amounting possibly to tons per square inch, may be produced by one of a series of parts that ought to act in unison, being exposed to the direct rays of the sun, while the others are in shade. In this way a difference of temperature of $30 \mathrm{deg}$. or $40 \mathrm{deg}$. may easily be produced, and the consequent difference of expansion will give rise to tempera- 
ture stresses of 2 to 3 tons per square inch, which are cumulative upon the ordinary stresses given by statical calculation.

That these temperature stresses really exist is abundantly proved by recent experiences at the great Moorabool Viaduct on the Geelong and Ballarat Railway. Here there are four precisely similar continuous girders, each 1300 feet long. They are completely sheltered from the sun by a broad overhanging deck that surmounts them, with the exception of the lower chord of the girder on the northern side. This chord consists of a number of eyebars placed side by side, and it was observed by the officers of the Railway Department that the outside bar when highly heated by the sun actually buckled under the compression, although at a part where the heaviest tension due to the load existed. The result of this buckling was to increase the stress on the adjoining bars by probably 30 per cent. To remove this serious source of weakness, a wooden roof, the whole length of the viaduct was erected over the chord so affected. This was undoubtedly the right thing to do, only, in the writer's opinion, an iron roof would have been more permanent and more in harmony with the monumental character and architectural pretensions of the structure.

This question of temperature stress ought to be looked into in the case of all girders that are partly or wholly exposed to direct solar radiation, and where it is found to exist in any serious degree, light screens or roofs of sheet iron should be introduced so as to ensure vital and highly stressed parts of the structure being always in the shade. As things are at present, it seems impossible to resist the conclusion that structures designed in the usual way for a working stress of 5 or 6 tons per square inch are frequently, owing to the combined effect of secondary and temperature stresses, subjected to actual stresses approaching double their nominal amount.

Further, it is recommended that girders exposed to the direct solar radiation be painted white, in order to keep them as cool as possible.

23. Insufficient lateral bracing.- The lateral bracing of the girders of existing bridges is various and inconsistent-in some cases being entirely absent and in others overdone at unnecessary expense. 
The older type of tubular bridges, such as the Footscray Railway Bridge, Victoria, and those at Menangle and Penrith. N.S.W., though presenting enormous surfaces to wind pressure, are invariably absolutely devoid of lateral bracing. They resist the wind simply by the resistance to bending of the main and cross girders in their weakest direction, and must be subject to extra stresses of serious amount in consequence. On the other hand, one not infrequently sees open lattice girders offering but insignificant surface to the wind, braced in the most costly and elaborate manner. Now, both these extremes must be wrong, and a discussion of what is really needed will be of advantage. A little consideration will show, as has been abundantly verified by experiments on models at the University, that a girder may be wrecked by lateral movement in one or more of the following ways:-

(a) It may fall over on its side, turning on its lower chord as an axis. This may be caused by wind or other lateral force acting on the top chord and web. The tendency will be greatest with deep and narrow girders, and becomes insignificant in the case of those that are shallow and broad. If the traffic is carried on the top of the girders this tendency may be effectively met by inserting a diagonal of sufficient section between the bottom of one girder and the top of the other at each point of support. This, with the cross girders, will keep all secure. Should, however, the traffic pass between the girders, as is often the case where headway is limited, such a diagonal is inadmissible. We must, therefore, make the base of the girder broad enough to secure stability, and carry a pillar up, starting the full width of this broad base, but tapering, if desired, toward the top, as indicated in Fig. 18, or, as an alternative, cross girders may be made continuous with stiff web members, so that the verticality of the plane of the latter is secured by the resistance to bending of the cross girder. Properly such cross girders should carry no load, for if loaded their deflection will affect the verticality of the main 
girder. This, however, can hardly be insisted upon in practice.

(b) The chords may be bent sideways by the pressure of wind upon the girder itself or upon objects supported by it. This pressure will be great in the case of plate web girders and of that chord of an open girder that carries the deck. It is to be met by inserting a proper system of diagonals forming with the chords of the main girders a complete horizontal trianguiation. It is certainly desirable that such a triangulation, made of stout $T$ or angle section, be added to the older tubular girder bridges and others that do not possess it. The smaller the width as compared with the span the more important this horizontal system is. There are some cases, however, in which it is not needed. The first is when the bridge is provided with a continuous metallic deck, as is now often the case. Such deck forms a most efficient horizontal web. The second is when the bridge is built on a skew such that the cross girders attached at or near the end of one main girder meet the other main girder at a fourth to a third of the span from one end. Here the cross girders themselves form an efficient bracing.

(c) The compressed chord may buckle or fail as a long column. To prevent this, it must be rigidly held at frequent intervals by some system of bars preventing any sma'l initial lateral bending from increasing. In an ordinary discontinuous girder the top chord is compressed, and if the deck is on the top, the same bracing that resists the pressure of wind on the top chord, deck, and load, will meet this requirement. If, however, the deck is on the bottom, 'the top chords may, if the girder be deep enough, be braced together overhead, with a complete triangulation extending from end to end. This is by far the most satisfactory method, and is usually found in the larger. American and European bridges of recent construction. If the headway is 
insufficient to permit this bracing, then the top member must either be of such a section as to be an efficient girder or beam in a horizontal direction, as for example the trough section usual on large lattice bridges, or be kept straight by some stiff construction continuous with the cross girders, and extending from the ends of these upward, and it is desirable that the cross girders be very deep and stiff. This is well arranged in the Toolamba Railway Bridge, Victoria, a section of which is shown in Fig. 45 , and in addition the bottom chords must be kept from bending horizontally by a stiff deck or complete horizontal system of triangulation.

Very often these requirements are met by projecting the ends of the cross girders some distance outside the main girders, and inserting an inclined strut from the end of the cross girder to the top of the main girder. If this system be used, these struts should be straight, of stiff section, capable of bearing compression as well as tension, and making an angle of about $30 \mathrm{deg}$. to the vertical.

The costly and complex arched connections extending overhead from one main girder to the other at the Footscray Railway Bridge, near Melbourne, and on most of the earlier railway bridges in New South Wales, are of very little value.

Existing bridges should be carefully examined, and if found insufficiently braced, have proper triangulated systems added, capable of bearing a wind pressure on the loaded structure of 20 lbs. per square foot, with a safety factor of at least 4 , and complying in all respects with the rules for pier bracing laid down on page $\mathbf{I} 2$.

Numerous errors occur in connection with the design and arrangement of cross girders in many early road and railway bridges; of these the following deserve notice:-

24. Cross girders or other local loads not placed in proper relation to the web system of main girders.-A most glaring instance is to be seen in the bridge carrying the Heidelberg and Eltham Road across the Plenty River, near Melbourne, shown in outline at Fig. 46. Here the main girders are of the $X$ type, and both triangulations are equally strong. The cross 


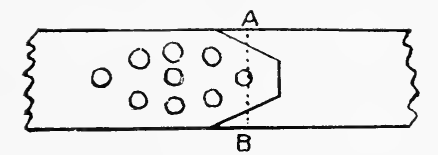

Fig. 38

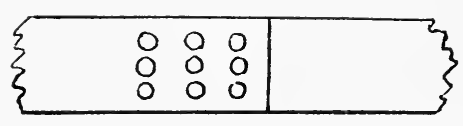

Fig. 39
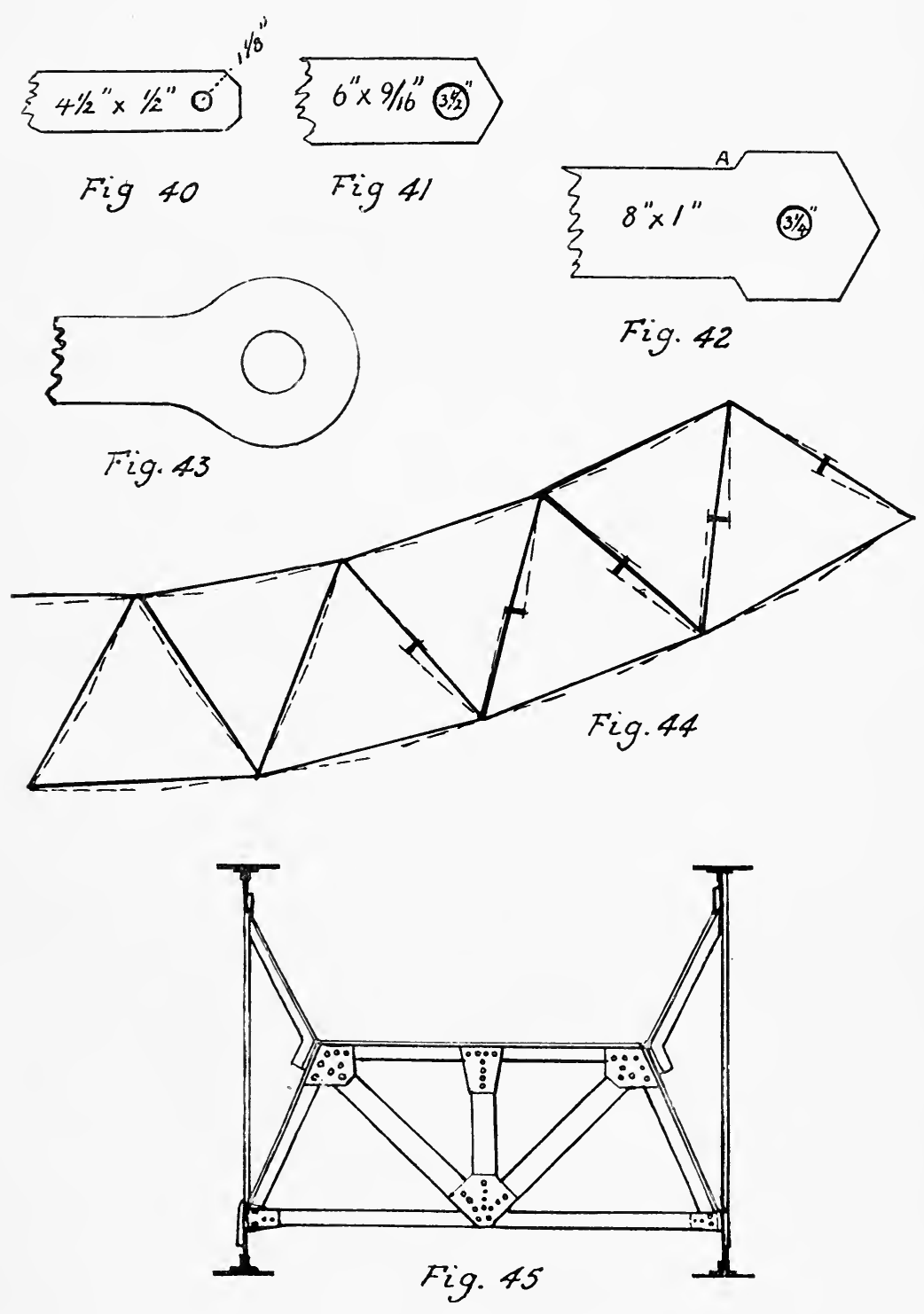
$m$ 
girders, however, are so placed as to discharge their load immediately upon the alternate panel points, so that in theory, at least, one triangulation carries the whole weight. Mr. J. A. L. Waddell, a leading American Bridge Engineer, to whom photographs and particulars of this structure were sent, expresses himself as follows :-

"For unparalleled ignorance and stupidity the triangular truss illustrated bears off the palm. It is almost incredible that any man with common sense could put in a whole system of triangulation where it is impossible for it to do any work whatever."

While generally agreeing with Mr. Waddell's drastic condemnation of the absurdity of this design, I question whether his closing words are strictly correct, for the following reason: If all the load was carried on one triangulation only, the panel points connected with it would deflect more than those connected with the unloaded triangulation, and thence the top and bottom chords instead of bending in an approximately circular curve would bend in a sinuous way, having numerous points of contraflexure. But such bending is impossible without evoking a considerable beam action in the chords, which are several inches in depth. Hence some part of the load must be transferred to the other triangulation. How much would be so transferred it is difficult to compute, but certainly not sufficient to cause even an approximate equalisation in the stress on the two triangulations. If we assume three-fourths of the total load to come on one and one-fourth on the other triangulation, we sha.l probably be taking a fairly favourable view. This bridge, undoubtedly, might be largely strengthened by inserting cross girders at all the panel points, and by replacing the thin flat diagonals near midspan of the main girders by proper double acting (strut and tie) sections capable of resisting the action of unsymmetrical loading.

Another example of a similar fault is to be seen in an impurtant bridge at Southampton, England, illustrated in "Engineering," 4th January, 1884, and criticised by the writer in "Engineering," 6th June, 1884. Here the cross girders are placed at intervals having no direct relation to the panel points of the main girder. At one point a cross girder comes exactly 
midway between panel points, thus bringing an unnecessary and undesirable bending moment of some magnitude upon the bottom chord.

A further instance of this fault was to be seen in the eastern extension of the Victoria Street Bridge, Melbourne, erected in I 884, and represented in Fig. 47. This, however, was remedied at the writer's recommendation.

25. Cross girders too numerous and individually too weak. -This fault is very commonly to be found in the earlier railway bridges of Victoria and New South Wales that have come under the author's notice. The heaviest local load to be provided for is that of the driving wheel of a locomotive, and amounts to slightly over 8 tons for one type of Victorian locomotive, and between 7 or 8 tons in several other types of engine. But it must not be forgotted that this load is liable to be largely increased, first by the downward resolved part of the thrust or pull of the connecting rod, and second by the effect of imperfect balancing, so that ro tons is the very least amount it would be safe to allow as the actual wheel load. Now, this load may come upon every individual cross girder in succession, and therefore every cross girder should be strong enough to resist it. At the same time there is no advantage in placing them nearer together than the minimum distance between the locomotive driving wheels, which is about 5 feet. Cross girders then, at not less than 5 foot intervals, each strong enough to carry the heaviest loaded pair of engine wheels, constitute reasonable practice, and many good recent structures correspond closely to this arrangement. On some of the earlier Victorian bridges, however, the interval is only 2 feet 6 inches, and in New South Wales 3 feet. The stresses in these girders are found by computation to be from 7 to $\mathrm{I} 2$ tons per square inch-very alarming figures. Looking at many of these earlier bridges it is difficult to understand why their bottoms have not dropped out long ago. It is, however, to be remembered that some of the worst have never been fully loaded, double line bridges as at Penrith in New South Wales, and Kororoit Creek, Victoria, carrying, hitherto, only single lines of way, while in most cases heavy timber longitudinals or stout continuous decks interposed between the track and the 
cross girders tend to spread the load and prevent any individual girder receiving its full punishment. Reliance upon these, however, is not advisable, as bad workmanship, decay and imperfect jointing may nullify their distributing action. The best thing to do with these weak girders is to introduce longitudinal connections of great stiffness between them. An arrangement in iron or steel similar to what is known as "herring boning" between the joists of a floor was recommended many years ago by the author for Penrith Bridge, N.S.W., see Fig. 48.

26. Improperly designed cross girders. - These occasionally occur, especially in the earlier bridges, and seem to have arisen from an ill-advised attempt to make the cross girders of similar type to the main girders. Badly designed lattice cross girders with vital junctions made by single rivets only, and heavy compressions taken on thin flat bars of considerable length were unfortunately to be found in some early Victorian bridges. Many have now been removed, and their places taken by substantial plate girders. As an example of most improper design, Fig. 49 may be quoted, which, not many years ago, was removed, after a quarter of a century of service, from an important bridge on a busy suburban railway near Melbourne. It will be seen that the tension on bar $\mathrm{AB}$ is ro tons per square inch, the shear on the rivet A, 8 tons per square inch, and pressure on the bearing area 25 tons per square inch-figures alarmingly high. The marvel is that such girders failed to cause appalling disaster.

It is fully illustrated here as a warning to bridge designers, and also as an encouragement; for the fact of these frightfully over-stressed constructions having carried a busy suburban traffic for a number of years without giving way, is a conclusive proof of the extraordinary endurance of the material, which was only iron, and an evidence of the wide margin of strength against unforeseen contingencies possessed by structures designed in a scientific way under usua: limitations as to permissible stress.

27. Unscientific forms of footpath brackets. - Many railway and road bridges are provided with overhung footways outside the main girders. The brackets supporting these should be rationally designed cantilevers continuous with the cross girders, and consisting of a proper top and bottom chord, and suitable 
web, either of continuous plate, or triangulated series of bars. Unfortunately, however, an unhealthy desire for ornament, overlooking the fact that the really beautiful must be based upon and grow out of that which is scientific and useful, has led many designers into extravagancies and absurdities. For example, the old Church Street Bridge, Richmond, near Melbourne, originally had footpath brackets made of thin round rods bent into the curves of a ram's horn, an absurd and excessively weak form, while the Swing Bridge at Footscray has the webs of its footpath cantilevers made of circular rings of $L$ iron, a costly and unscientific arrangement, the exact strength of which it is impossible to compute. It is suggested that such brackets be carefully examined, tested, and if showing any signs of weakness, strengthened, and that in future structures, scientific and rational forms be adopted.

28. Parapets too low, too weak, or too open.-These are of not uncommon occurrence, and as sources of danger to the public are frequently of serious import. An examination of such parapets on bridges in or near Melbourne has revealed the fact, that some are less than 3 feet in height, while others approach 5 feet. The former are certainly dangerously low, the latter needlessly high. It is recommended that no bridge parapet should be less than 3 feet 6 inches, which is the height of the elbow of a man of medium size, while 4 feet may be taken as a maximum beyond which it is unnecessary to go. The same rule should, in the writer's opinion, be applied to the balustrades of staircases, landings, and balconies in buildings. These are usually too low, and have repeatedly been the cause of serious accidents.

No rule has been to the writer's knowledge generally accepted for the strength of parapets. He therefore proposes that to provide for the pressure of a dense crowd, they be made strong enough to endure a horizontal pressure of 100 lbs. per foot in length, applied at the top with a safety factor of not less than 3 for metal and 5 for timber.

This strength may be provided by the resistance to bending of the uprights or standards of the parapets. But if this be found to involve an undesirable amount of material, lighter standards may be employed, with sloping struts outside. These 

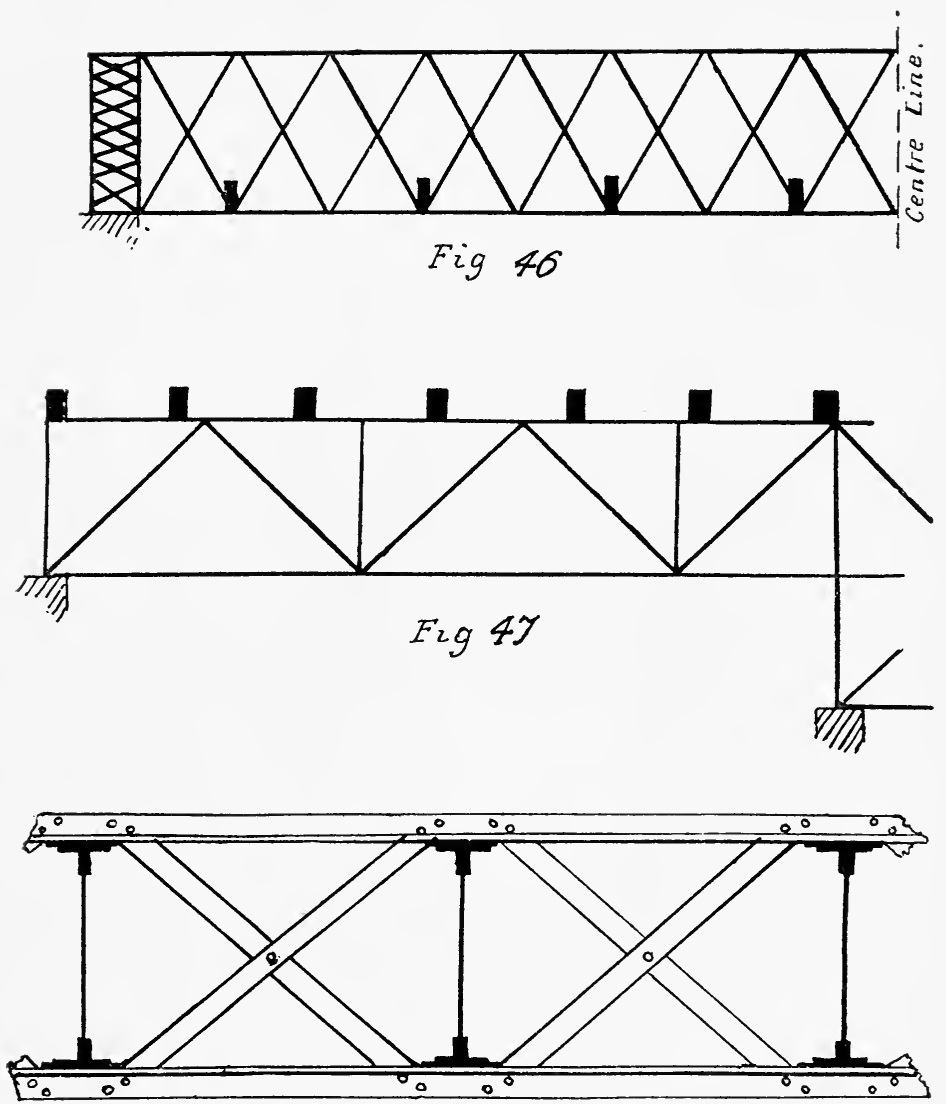

Fig 48

1

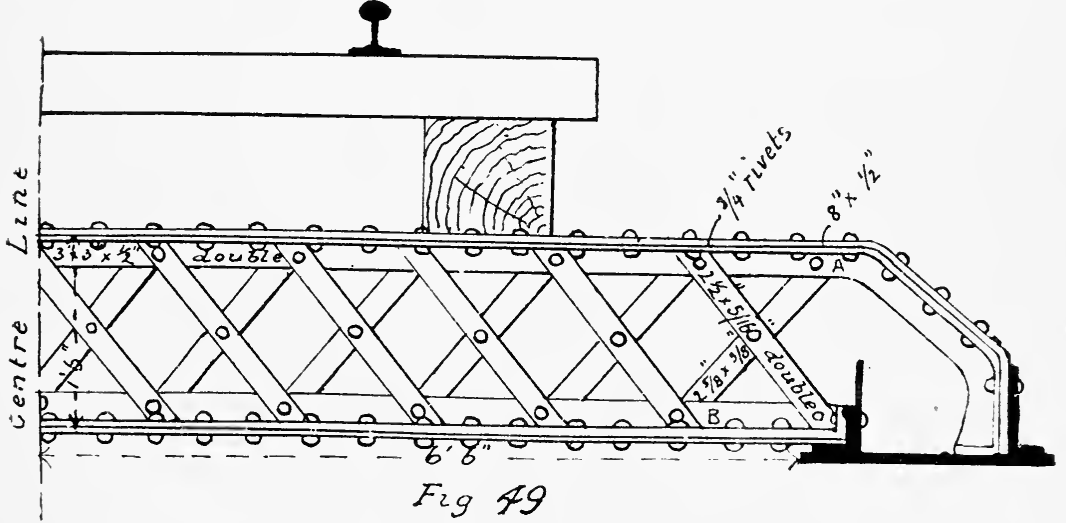
Fig 49 
TIBKA TE

UNIVERSITY

of

* CALIFORM 
struts should be straight, inclined at an angle of not less than $20 \mathrm{deg}$. to the vertical, and extend from the projecting end of the footpath cantilever to a point about three-fourths of the height of the parapet. They may be made of angle, $T$, channel, or any other stiff section of meta! and securely riveted or bolted top and bottom. In some recent and otherwise excellent bridges near Melbourne, small triangular plates of thin metal riveted along the bottom and the vertical side have been used. These are not to be commended, as the maximum compression comes on the thin edge of the plate that is least able to endure it, and the majority of the rivets are placed where they endure but little stress and are of proportionately little service. The same amount of material and labour put in a substantial sloping strut would give far greater strength.

A parapet may be high enough and strong enough, and yet a source of danger by having openings in it large enough for children to pass through. An examination of a considerable number of such parapets leads the writer to recommend that if formed of parallel horizontal bars, these bars should not be more than 9 inches apart vertically, or if as is often the case formed of lattice work showing square openings, such openings should never be more than I foot square. It is recommended that all parapets accessible to the public be altered when necessary to comply with the above requirements.

29. Metallic arches. - Where sufficiently massive abutments are easily obtainable, and there is fairly ample headway, wrought iron or steel arches may be rather more economical than girders, as well as far more pleasing in appearance. Their proper design and execution is, however, a matter of special difficulty and care. To calculate the effect of irregular loading, and variations of temperature, involves difficult mathematical investigations beyond the power of the average engineer.

Metallic arches are either without hinges, with hinges at the springing only, or with hinges at both the springing and the crown. The first suffer most from temperature stresses, the second suffer less, and the last are practicaily free from them. On the other hand, hinges are expensive, and the money they cost would pay for a very substantial addition to the sectional 
area of the arch; a'so the unhinged arch is usually firmer and less subject to vibration. The largest existing steel arch crosses the Niagara River just below the falls. It is over 800 feet span, and is hinged at the springing only. The arch rib itself is a Warren girder. A successful example of a wrought iron arch is shown in Fig. 54 in the background. It was erected rather more than $3^{\circ}$ years ago, and is of the following dimensions :-Span, roo ft.; Rise, I rft. 9 in.; Depth of arch, $2 \mathrm{ft} .6 \mathrm{in}$. Section of top and bottom members, 26 sq. in.; Thickness of web, $\frac{1}{2}$ in. at ends, $\frac{1}{4}$ in. at centre; Distance between arches, $16 \mathrm{ft}$; Width of deck, 2 I ft.; No hinges.

Calculation shows that an unhinged iron or steel arch attains its maximum strength at about 20 degrees $\mathrm{F}$. above the temperature at which it was accurately and without stress fitted into its place. Hence this fitting-in should take p'ace that amount below the average temperature. If fitted in at the average temperature, its strength becomes seriously impaired in cold weather. The author has known this error to have been made in at least one important case.

30. Unstiffened suspension bridges. - The number of small suspension bridges for foot passengers or light traffic is increasing, and in view of their cheapness and the unobstructed waterway they provide, this is a tendency rather to be encouraged. A great defect, however, in many is the lack of rigidity. They change form greatly during the passage of a load, working and chafing all their joints and alarming horses or timid foot passengers. Further, during high winds they are sometimes thrown into such a state of violent agitation as to be seriously injured. Extreme examples of this occurred at the Brighton chain pier, in England, and at the suspension bridge which formerly stood just below the Niagara Falls. In each of these cases, on the storm passing over, nothing remained of the decking, cross-girders, or handrails-the main cables and vertical suspending rods being all that outlived the gale.

Now how shall such a structure be made reasonably rigid? The natural way is by combining the suspension system with some sort of a girder. But if this be done the difficulty arises that in warm weather the chain or cable lengthens, sags and throws most of the load on the girder, whereas in cold weather 
it shortens, rises, and lifts the girder off its supports, or if the latter is bolted down a conflict arises, chain and girder pulling against and endeavouring to destroy each other.

To harmonise these two discordant elements is a matter of some difficulty. One way is to hinge the girders at the ends and centre, and this has been successfully applied in two large suspension bridges in New South Wales. The strength of girder needed is that which will without the chain carry half the live load per foot run over half the span of the bridge, and this, of course, is very small compared with a girder to carry both dead and live load over the whole span without the aid of the suspension system. It must not be forgotten, however, that the girders must be anchored down at the ends and made double-acting; that is to say, capable of bearing the load if it acts upward, as it does on the unloaded half of the bridge. On the other hand, a comparatively small factor of safety may be employed in these girders, because, even were they to give way, no great disaster would ensue, the bridge merely changing from a stiffened to an unstiffened one. This has actually happened to the great Brooklyn Bridge in America.

Another way is to have a continuous unhinged girder, and make it so shallow that it will deflect to the extent of the varying dip of the cable without being too seriousiy stressed, and yet deep enough to afford the desired rigidity. With a cable dipping about one-tenth of the span, and a girder having a depth of not more than one-sixtieth of the span, this works fairly well. A third plan sometimes adopted is to connect the suspension cable and the deck, not by a series of vertical rods, but by a zigzag arrangement like the letter $\mathrm{W}$ repeated. This requires the suspenders to be fully twice as strong as if vertical and parallel, but gives considerable rigidity. This is the system adopted at the fine suspension bridge at Rockhampton, Queensland. At North Melbourne there is a very successful suspension footbridge of considerable span crossing lines of railway. It really acts as a cantilever for about a fourth of the span at each end, while the central part is provided with stiffening girders hinged at ends and centre. The main cable here consists of railway rails connected by specially long and strong fishplates. They form a very substantial and durable cable, 
but are heary and difficult to erect as compared with a wire rope.

31. Workmanship.-While the present treatise ostensibly deals with the design of bridges only, it may not be altogether inappropriate to point out very briefly the principal exampies of bad workmanship that have met the writer's eye during a fairly lengthy and diverse experience. They are as follow:-

I. Inaccuracy of form.-Carelessness in assembling the parts of a bridge before riveting sometimes results in unsightly curvatures in parts meant to be straight. This cannot be rectified without cutting out rivets. Too much care cannot be taken when the girder is vet unriveted, but in a flexible condition, held together by loosely-fitting bolts, to adjust every part most accurately in its final intended position. At this stage the question of camber should be considered. As a matter of pure theory, the correct camber of a girder is such that under its maximum possible load the camber just vanishes, and every part assumes the position postulated in the calculation of stress. But this is not a matter of much practical importance. The camber may be varied from nothing at all, or even a negative value, to an amount several times greater than is commonly adopted, with no really important effect on the stresses. A liberal camber has the advantage of giving an appearance of strength and favourably impressing the public, who are liable to be alarmed at a real or even only apparent absence of camber. Girders with a varying depth, such as are known as bowstring or hog-back girders-of which a fine example carries the Gippsland railway over the Yarra at S. Richmond, Fig. 5I-should be given an abundant camber, at least twice as great as parallel girders would need. The reason is an optical effect of contrast, which tends to make the bottom member appear to be sagged even if given the usual camber upward. Camber is really a matter of appearance and of mental effect on the onlooker. 
2. Want of correspondence of rivet holes.-In the old days of punched work, this was often a serious evil. No matter how carefully the holes were marked out, the stretching of the metal in the process of punching would often cause a want of correspondence, and then violent and injurious methods were employed to force the plates into their right position, giving rise to unknown stresses of serious import. In the modern system of drilled work this evil has almost vanished. In high-class modern work the parts are carefully clamped in their intended position, drilled through all the thicknesses at once, taken apart, the sharp edges of the drilled holes scraped off by an S-shaped steel tool, then re-assembled, adjusted most carefully and accurately in their final positions, and finally riveted, preferably by some mechanical app'iance giving a steady squeeze rather than a series of blows.

3. Bad riveting.-There are several varieties of this fault. First, the heads may not be close down on the plate; second, the various plates riveted through may not be in contact, but may be actually held apart by a bulging projection on the stem of the rivet; third, the rivets may be loose to a greater or less extent; fourth, the heads may be hoilow; fifth, the heads may not be symmetrically placed on the stem of the rivet; sixth, the rivets may be of lead, putty or clay.

The first and second of these faults will be obvious to the eye, and the third may also be, as loose rivets often give rise to a stain of rust. It is desirable, however, to test rivets by tapping them lightly with a small hammer, placing a finger on the opposite side of the head to that tapped. Rivets should be tested at both ends, especially if passing through many thicknesses of metal, for they may be tight on one side and loose on the other. In fact, it is very undesirable to attach more than three, or at most four, thicknesses by one' set of rivets in the author's opinion, on account of this tendency. 
The fourth fatilt occurs when the rivets supplied to the riveters have been too short. The author once met with a bridge which to mere eye inspection was perfect, but a comparatively light blow would send any rivet out, ail that was left of the head struck being a thin, flat piece of iron like a small washer. The men had succeeded with gent.e blows and finishing with a cup in making a head that contained less than half the metal it appeared to. Of course the rivets were all loose in their holes.

The fifth fault may sometimes be detected by looking at the edges of the plates, when the two heads of a rivet will often be seen not to correspond, as they should. The most thorough test is to cut off one head of a rivet by a chisel, and drive the rivet out by a punch. This will at once show if the heads are symmetrical and the rivets tight in their holes. A good rivet should take two or three blows of a six-pound hammer to drive it out after its head has been cut off.

The sixth fault might appear incredible, but the author has seen and tested both lead and putty rivets in some of the largest bridges in Australia, and has heard of clay rivets in a large structure in Ireland. While such things are deserving of the severest punishment to those perpetrating them, the designer is not always free from blame, for he, by needlessly placing rivets in awkward positions where they could not be properly riveted, has often led his humbler brother into temptation. The inspector of riveted work should therefore give the closest attention to any parts where there is more difficulty than usual in doing sound work.

If a serious amount of bad riveting occurs in any bridge it should be cut out little by little, at times when the structure is not heavily loaded, and replaced by sound work. As many old structures are considerably over-riveted, a few loose rivets in places where the stress is small need not cause uneasiness. If, 
however, tight rivets are continually becoming loose, and there are symptoms of movement of the plates on each other, the probability is that the part is over-stressed, and proper calculations of strength should be at once made. In fact, it is only right to say that no one can properly inspect either a new or old structure without a complete knowledge of the stresses throughout. Wanting this knowledge he may cause annoyance and expense by insisting on the rectification of unimportant faults in parts that are very lightly stressed, or, on the other hand, may condone defects in places where they are of most serious import.

4. Parts of bridges lost or misplaced.-In some old bridges the author has found minor diagonals forming parts of latticed struts sometimes missing, the holes for the attaching rivets testifying to the loss. Of course this, if in vital parts, might entail disaster. Again, angle and plate covers are not infrequently wrongly placed. For example, a cover may have holes for six rivets, three on each side of the joint, but if placed one rivet space out of position will have only two rivets on one side, and four on the other side of the actual joint, leading to 33 per cent. loss of strength. This fault is not uncommon on old bridges. Of course it should be at once rectified when discovered, and a'l lost parts replaced.

32. Care and Maintenance.-Though hardly coming under the title of this work, these matters are of such vital importance, and often so scandalously neglected, that it seems a pity to neglect the opportunity to make a protest against treatment that has in many cases caused great difficulty in judging as the strength of old bridges, and in many others has shortened the life of costly structures. The following recommendations are therefore made :-

(I) On the completion of every bridge a set of records should be collected and preserved for future reference. They should include:- 
A correct set of drawings of the work as executed, showing all departures from the original design, and stating cause or reason of same; also copy of specification;

A stress sheet showing anticipated loading, and stresses due to same;

A statement of actual tests of the materials used, noting any departure from the specified tests, and the reason for same;

A statement of results of actual deflection or extensometer tests made on the completed structure ;

A set of very accurate levels taken on marked points over each support, and at the centre of each span.

The last of these requirements may appear unusual, but it is specially needed for continuous girders where any alteration in level of supports seriously affects the stresses. The writer has had to do with a case in which it was of great importance to know whether a difference in level of the piers was due to error in the original construction or subsequent sinking of foundations. If the first, it was innocuous; if the second, it was serious. In all bridges, also, it would enable the camber to be tested from time to time, and any change noted. In connection with this point, it is to be noted that ordinary girders unprovided with freely-moving expansion apparatus tend to show less camber in winter and more in summer. To determine, then, whether a bridge is losing its camber or not, the tests should be made at some known and recorded temperature.

(2) Both at first and afterward every possible precaution should be taken against corrosion, especially if the structure be near the sea or exposed to corrosive fumes from metallurgical or chemical works in the vicinity, or from locomotive engines passing beneath. For this purpose all parts of girders should be accessible to air, light, and inspection, and should be 
kept thoroughly dry. Horizontal surfaces exposed to weather on which water may stand should have an extra coat of paint or other preservative. Trough bottom members should be extra well painted inside, and drainage holes provided to let rain water off; and care should be taken to prevent accumulation of dust or horse-dung in them. Small spaces that are not easily painted or inspected should be filled up with cement or tarred screenings. In plate girder road bridges, with a sunken deck, a gap of at least two inches should intervene between the web and the side of the deck to permit painting.

Every few years the bridge should be carefully inspected, thoroughly cleaned, and then painted. The evil of painting without previous cleaning and inspection was evidenced not many years ago in the great Brooklyn Bridge, New York. Serious fractures having taken place, it was found that important moving joints providing for variations of temperature had been allowed to set fast by rust and dirt, and in that state thickly painted over. They ought to have been kept clean and lubricated like the bearings of an engine. Finally it is important that all this work be done intelligently and with knowledge of the stresses, the greatest care and most frequent inspection being given to structures or parts of structures having the smallest factors of safety, or exposed to actions producing corrosion.

For further information see the author's paper on "Maintentenance of Iron Bridges," Victorian Institute of Engineers, vol. iv., p. 90.

\section{Suggested Specifications for Steel and Rivets, also Loads and Safety Factors for Road Bridges.}

I. The steel to be made from an open hearth furnace; to have a tensile strength of not less than 57,000 or more than 70,000 lbs. per square inch, with an elongation of not less than 20 per cent. on a test piece 8 inches long, and not less than half nor more than one square inch sectional area. 
The steel must bend cold 180 degrees round a diameter equal to the thickness of the specimen, or when quenched in water of 80 degrees Fahrenheit, after having been heated to a dull red, must bend round a diameter three times the thickness of the specimen without showing any cracks.

2. The rivets to be of a somewhat softer steel of $5^{\circ}, 000$ to $60,000 \mathrm{lbs}$. tensile strength, with 25 per cent. elongation, and the rod from which they are made must bend cold 180 degrees flat on itself without showing any cracks on the outside of the bent part. Cracks are likely to occur on the inside, but they do not matter.

\section{Loads.}

A crowd of 100 lbs. per square foot over the whole area of the deck, or $15^{\circ} \mathrm{lbs}$. per square foot over the area carried by one cross girder or footpath bracket or a steam roller of 20 tons weight, occupying a space $\mathrm{I}_{5} \mathrm{ft}$. long and $8 \mathrm{ft}$. wide, supported on four wheels. In remote places of little traffic these loads may be reduced by 30 per cent.

\section{Safety Factors for Road Bridges.}

Absolutely unvarying stress, 3 .

Stress having a minimum half its maximum, $3 \frac{1}{2}$.

Stress varying from zero to a maximum, 4 .

Stress reversing from tension to compression, the smaller stress being half the larger, $5 \frac{1}{2}$.

Stress varying from tension to compression of equal value, 7 .

Parts exposed to special jar or sudden shock to be made $3 \circ$ per cent. stronger.

Shearing stress on rivets not to exceed 85 per cent. of the tension on net section of bars connected, and pressure of rivets on the diametrical projection of the bearing surface not to exceed twice such tension.

For compression members flat bars may be used with above safety factors if fixed in direction at the end, and having a free length between points of attachment which does not exceed $3 \circ$ times the thickness. If the free length is more than 30 , but less than 40 , times the thickness, they must have $5^{\circ}$ per cent. more sectional area; if the free length is more than 40 , but less 
than 50 , times the thickness, double sectional area. Beyond this proportion it is not desirable to use flat compression pieces.

Angle $\mathbf{T}$ and channel bars may similarly be used without extra safety factors up to a length of 20 times their least transverse dimension, with 50 per cent. additional area up to 30 times, and with roo per cent. additional area up to 40 times.

Note.-For the benefit of students of bridge work residing in or visiting Melbourne, the following bridges are mentioned as easily accessible and worth examining. Photographs are appended, which may facilitate their identification, and may possibly prove of some use and interest to such as are unable to personally inspect the actual structures:-

Fig. 50.-Victoria Street Bridge, reached by tramcar from Collins Street. Girders of unusual by highly effective design, $55 \mathrm{ft}$. span, and only $3 \frac{1}{4}$ tons weight each. A model of one of these girders was tested to destruction at the University, and beat a number of competitors, both of British and local design. For comparison with ordinary $\mathbf{X}$ girders see Victorian Institute of Engineers, Vol. VI., p. I67. Similar girders are to be seen at the bridge over the Thomson River, Toongabbie and Walhalla Road, Gippsland; also, slightly modified to suit local conditions, at Corra Lynn, near Launceston, Tasmania, and elsewhere. Of course this type can be used only in the somewhat rare case of there being ample headway, and further needs effective lateral bracing to keep it in a vertical plane. Taking the cost per square foot of waterway, or per square foot of deck area, this is the cheapest iron bridge known to the author. The photograph represents it as originally built. Subsequently it was made both longer and wider, but the additions do not compare favourably with the original structure, either as regards design or workmanship.

Fig. 5 I represents the new Cremorne Railway Bridge, carrying the Gippsland Railway over the Yarra. It is reached by a few minutes' walk from the South Yarra railway station, and as it carries a public footway is convenient for detailed inspection. The main hog-back girder is $140 \mathrm{ft}$. effective span, and nearly $20 \mathrm{ft}$. deep. The design is admirable from the point of view 
of economy of material, but owing to the curved top member and the varying lengths and slopes of the diagonals, the workmanship is rather more complicated and costly than that of a parallel girder. Note specially the simple and effective compression diagonals, the correctly triangulated footpath brackets, the well-arranged lateral or wind bracing, and the excellent workmanship. This bridge is of steel, was completed in 1886 , and the superstructure is reported to have cost about $£ 9000$, while the masonry and foundations cost about $£ 8000$. Similar girders are used for large railway and road bridges in Queensland and elsewhere. From an æsthetic point of view this bridge is very fine.

Adjoining it is a bridge about 30 years older, which originally presented many of the worst faults commented upon in this treatise. About 20 years ago, however, it was reconstructed, new cross girders and lateral bracing being provided, insufficient cover plates being replaced, and weak diagonals reinforced. It may now be regarded as a reformed character, and a good example of how to improve and utilise an old and defective structure.

Fig. 52 represents the railway bridge between Burnley and Heyington, which may be reached by a short walk from either of these stations. It also has a public footway that facilitates inspection. It is an example of modern lattice girder work of simple design and good execution. Of somewhat lighter scantling it would make a very satisfactory road bridge. The author regards the columns as unduly massive.

Fig. 53 represents the Whipple truss footbridge connecting Burnley Street, Richmond, and Wa'mer Street, Kew, while in course of construction. The Victoria Street tramcar passes within a few yards of it. The general design is economical and simple, but the compression verticals and the lack of adjustments in the counterbraces are subjects of criticism. Also it seems a pity to put so unæsthetic a design at a picturesque part of the river, and near a number of costly and beautiful residences. A similar structure crosses the river at Hoddle Street about half-a-mile west of the Cremorne railway bridge. 


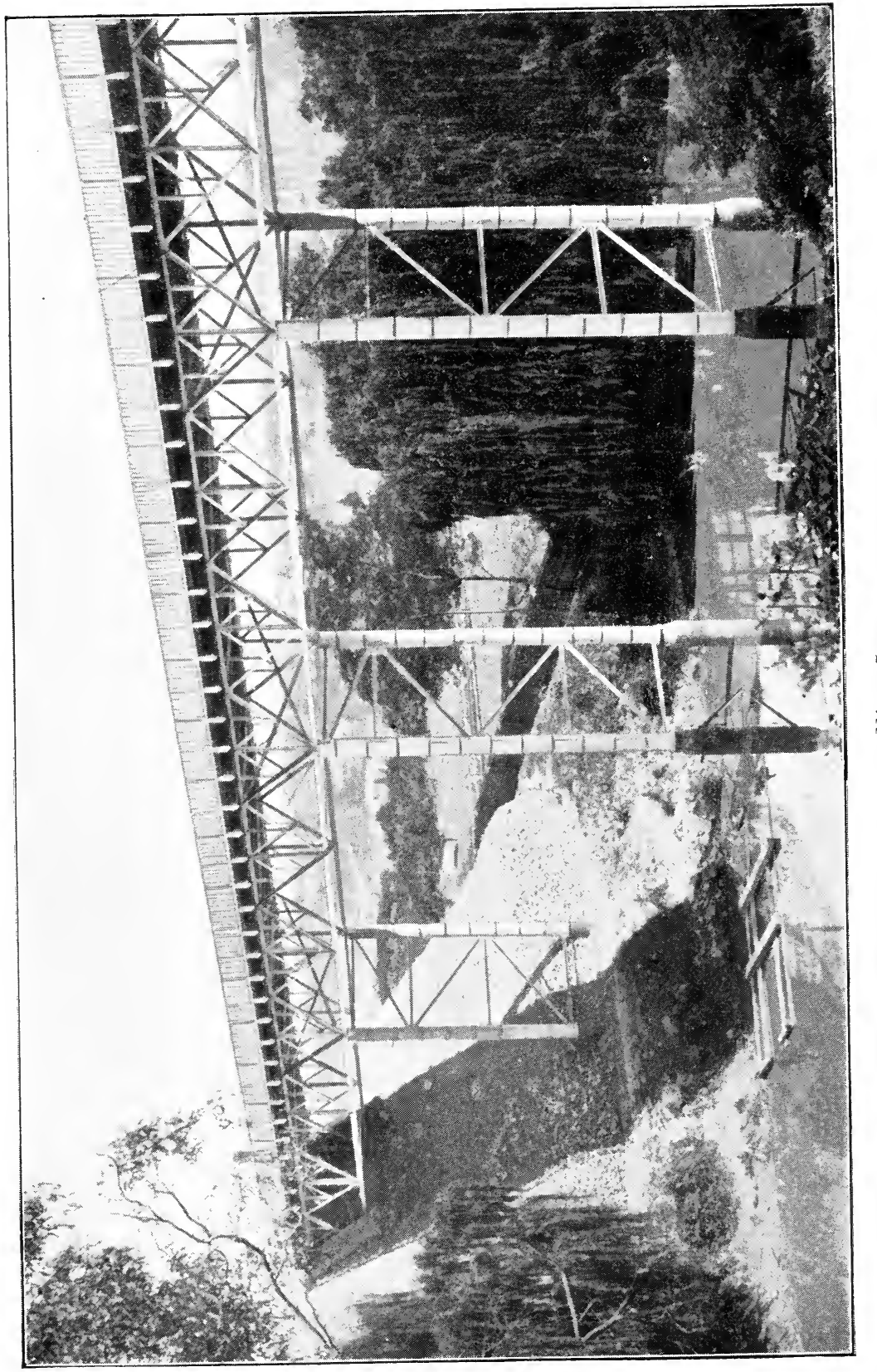


<smiles>[CH]1CCCC1</smiles> 


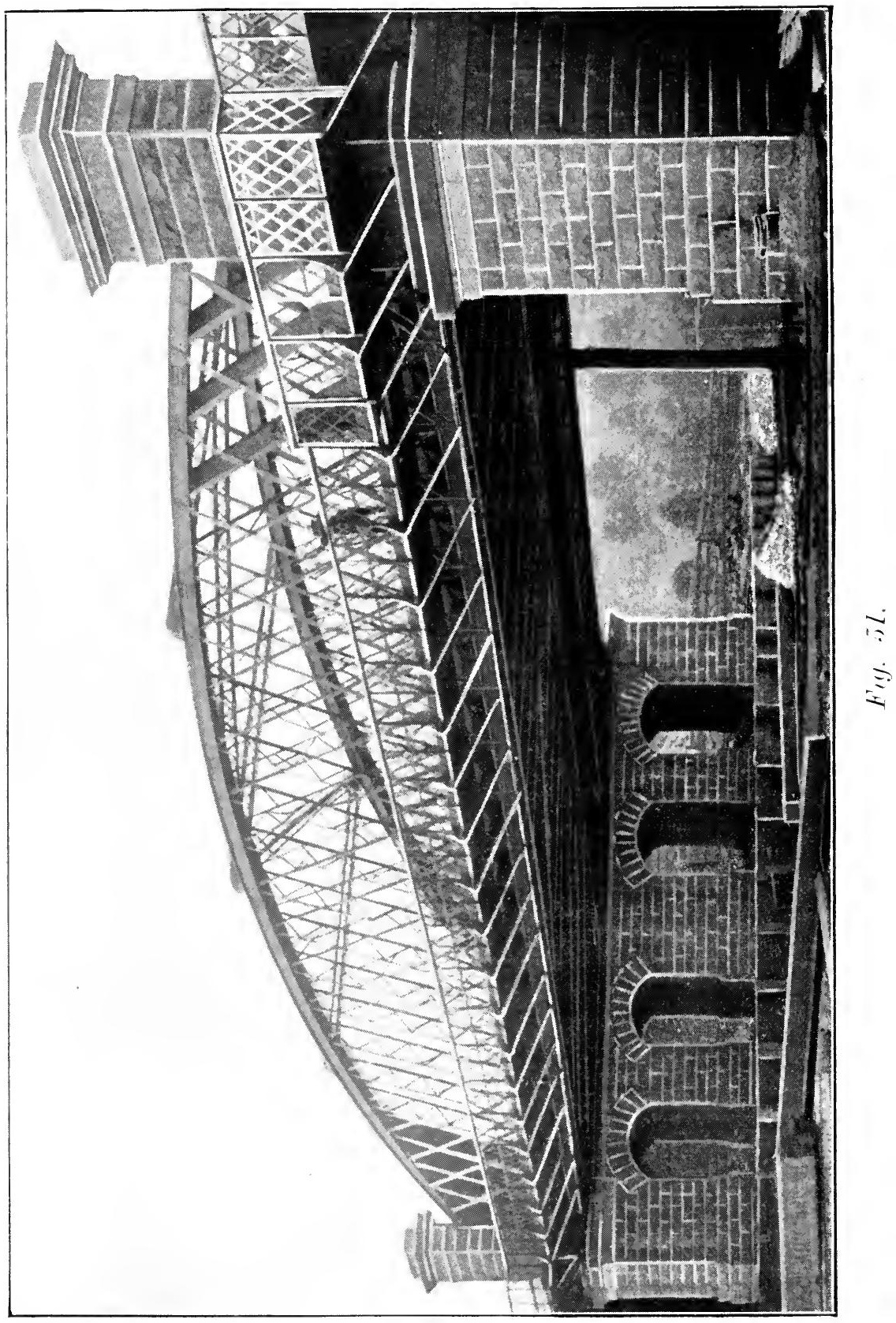



Fig. 54 represents a light Warren girder structure carrying a water main over the river at Heidelberg, about 8 miles from Melbourne. As the load is uniformly distributed, no double-acting diagonals or counterbraces are needed. The design is simple and effective, and very free from secondary stress.

Of other bridges worth notice may be mentioned those recently built over the Moonee Ponds Creek and Saltwater River on the road from North Melbourne to Footscray.

Of plate girder work many up-to-date examples may be found, in the elevated railways both north and south of the Yarra, near the Flinders Street station. The bridge over the river is specialiy interesting, as is also the ingenious curved cantilever structure at the intersection of Flinders and Spencer Streets.

Other structures too numerous to be mentioned are to be seen throughout Melbourne and its suburbs-some meritorious, some the reverse-but those already mentioned will suffice as being typical, modern, and accessible.

\section{Note on Calculations of Stresses.}

These calculations merely need a knowledge of the composition and resolution of forces, and the principles of leverage or mołment, as far as primary stresses only and simple forms of frame are concerned. Take, for example, Fig. 53, and suppose that there is a load of 5 at the bottom end of each vertical. As there are 9 of these, the total load will be 45 or 22.5 at each end. As the compression of the end diagonal or batter brace must supply a vertical resolved part equal to the supporting force, it must be $7 / 5$ as large, this being approximately the secant of 45 degrees. Thus it becomes $3 \mathbf{I} \cdot 5$, and its horizontal resolved part causes a tension on the bottom chord of 22.5. At the top end of the batter brace the vertical resolved part of 22.5 partly resists the tension of 5 on the vertical due to the load at its lower end, and partly causes a tension of 24.5 on the next diagonal. This in turn carries a load of 5 , and also gives a compression of $\mathbf{I} 2.5$ on the next vertical, and so on. At the top chord the end panel carries a compression of 40 , being the sum of 22.5 from the batter brace, and 17.5 from the 
next diagonal. This increases at the next panel to $5^{2.5}$, owing to the horizontal effect of the $17 \cdot 5$, and so on. The final results will be:-Top chord, 40, 52.5, 60, 62.5 compression; bottom, $22.5,22.5,40,52.5$, 60 tension; diagonals, 31.5 compression, 24.5 , I7.5, 10.5, 3.5 tension; verticals, 5 tension, I 2.5, 7.5, 2.5 comqression. For an irregularly distributed load. multiply each load by its distance from one end of the girder, add the products together, and divide by the length of the girder. This will give the supporting force at the other end. Taking this from the total load, we have the supporting force at the first end. Then proceed to calculate as before. For a 60 degree triangulation, as in Fig. 54, if we call the load at each cross girder 7 , the total load becomes 35 , each supporting force $\mathbf{1 7 . 5}$. Then, remembering that sine 60 degrees is $\frac{7}{8}$, and $\cos 60$ degrees, $\frac{1}{2}$ very nearly, we shall have the following results:-Top chord, 20, 32, 36 compression; bottom chord, 10, 26, 34 tension; diagonals, 20 compression, 20 tension, I 2 compression, I 2 tension, 4 compression, 4 tension. As the load is always equally distributed, there is no need of further calculation. An $X$ or lattice girder may be divided into two or more separate girders, each consisting of one continuous set of diagonals, and a share or portion of the chords. The bracing of piers may be similarly computed, the horizontal force of the wind or flood being taken as the load. In some cases a dead or unstressed triangle is found as at the left hand end of Fig. I4.

The following rules may be of use to those not specially expert in these calculations:-

I. The greatest stresses in the chords and end verticals and diagonals of parallel girders occur under the maximum load.

2. The greatest stress in any other diagonal or vertical occurs when the live load extends from it to the further end of the span.

3. The least stress in the chords, end verticals and diagonals occurs when the live load is entirely absent.

4. The least stress in any other vertical or diagonal occurs when the live load extends from it to the nearer end of the span. This least stress may in extreme cases be a reversed stress-that is, a tension when there was compression under the full load, or vice versa. 
CALIFORNIA 


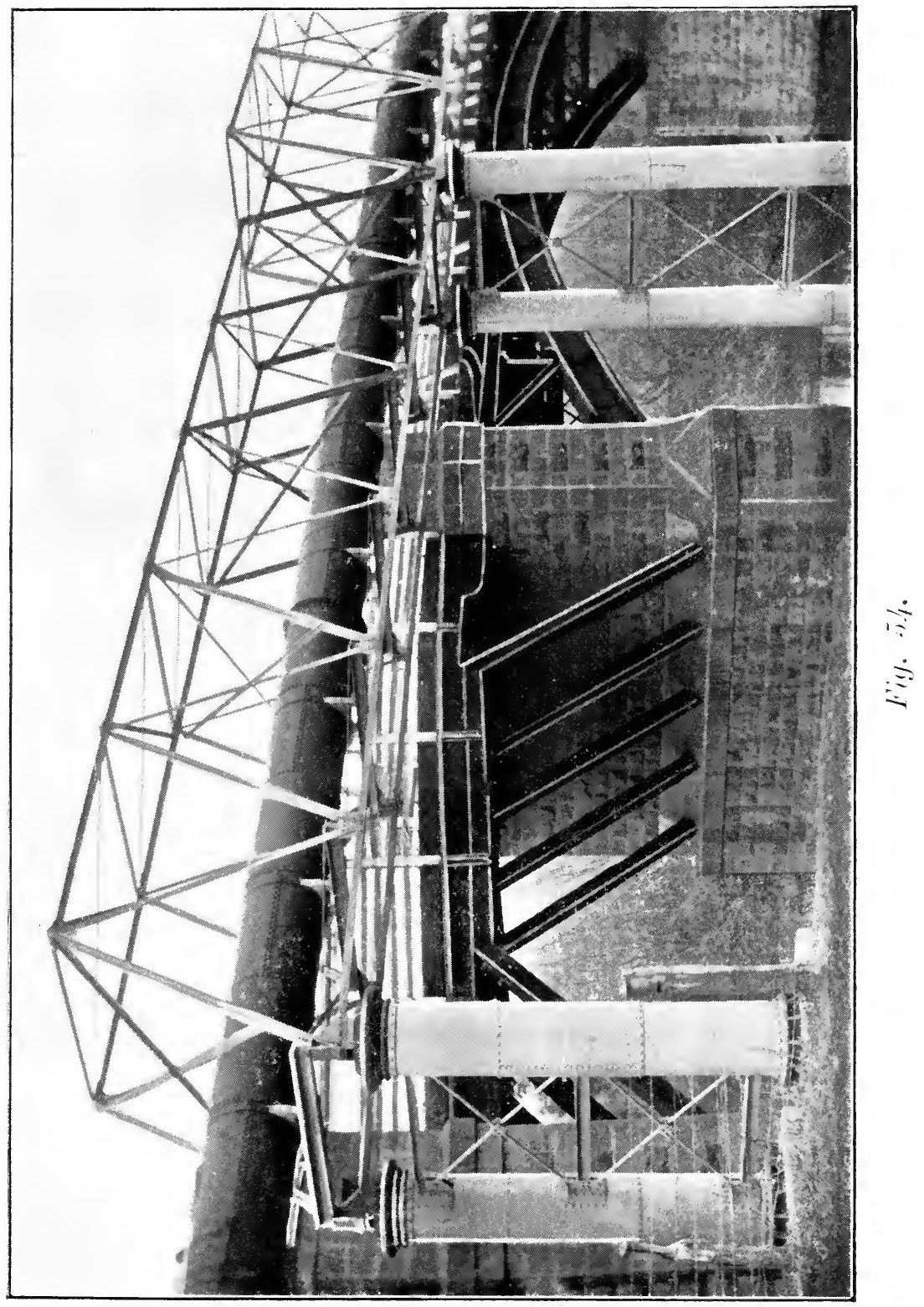


<smiles>CCCCC</smiles> 
5. The maximum stress in either chord is in the centre, and diminishes gradually to each end. If the depth is one-eighth of the span, it is approximately equal to the total load; if the girder is shallower than one-eighth, the stress is proportionately greater; if deeper, proportionately less.

6. A good, rough approximation to the stresses and sizes in an ordinary $\mathbf{X}$, lattice, or Warren girder may be made as follows:-Take the stress at the centres of the chords as above and reduce it gradually to half the amount at the ends; make the end vertical, if there is one, as massive as the adjoining parts of the chords.

If there is one system of triangulation, as in Fig. I4, the stress on the end diagonal will be half the total load multiplied by $\frac{7}{3}$ if the diagonals are at 45 degrees, and by $\frac{8}{7}$ if they are at 60 degrees. If there are two systems of diagonals, as in Figs. I 5 and 29, each will bear about half the stress thus computed, if four, as in Fig. I2, one-fourth. Reduce the sizes of the diagonals gradually to about half at the mid-span. Remember to make the compression diagonals-that is, those that point upward toward thecentre of span-of stiff sections, and for about the central third of the span make all diagonals stiff, so as to be capable of bearing either tension or compression, and so provide for partial loading. Of course this rough method should not be used for the final design of a costly structure, but merely for first approximations and rough estimates; nevertheless, it is not impossible to point out important structures that would have been decidedly improved if it had been employed.

For the computation of hog-back girders, Fig. 5 $\mathrm{I}$, continuous girders, cantilevers, subsidiary triangulations, Fig. '50, arches and suspension bridges, the reader is referred to standard works on stress calculations. For many of these Maxwell's reciproca! diagram, with Bow's system of lettering, is most convenient, and is therefore recommended. For continuous girders, Clapeyrons' Theorem of Three Moments is very useful, but very good experimental results may be obtained by using an ordinary $6 \mathrm{ft}$. steel straight edge, supported on accurately levelled supports and suitably loaded. Testing with a good spring balance the force required to lift the straight edge off each of its supports, information is obtained by which moment and shear diagrams, 
and ultimately chord and web stresses, may be computed. The writer would here commend to the learner the practice of making cardboard models of various forms of girder, and testing them to destruction. He himself in early life gained much from this practice, and he feels sure that many of the anomalous structures he has inspected would never have been built had the designer experimented beforehand on a cardboard model.
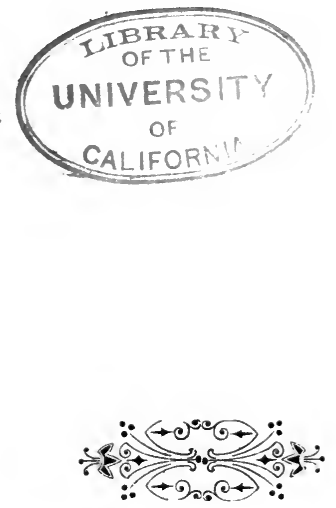




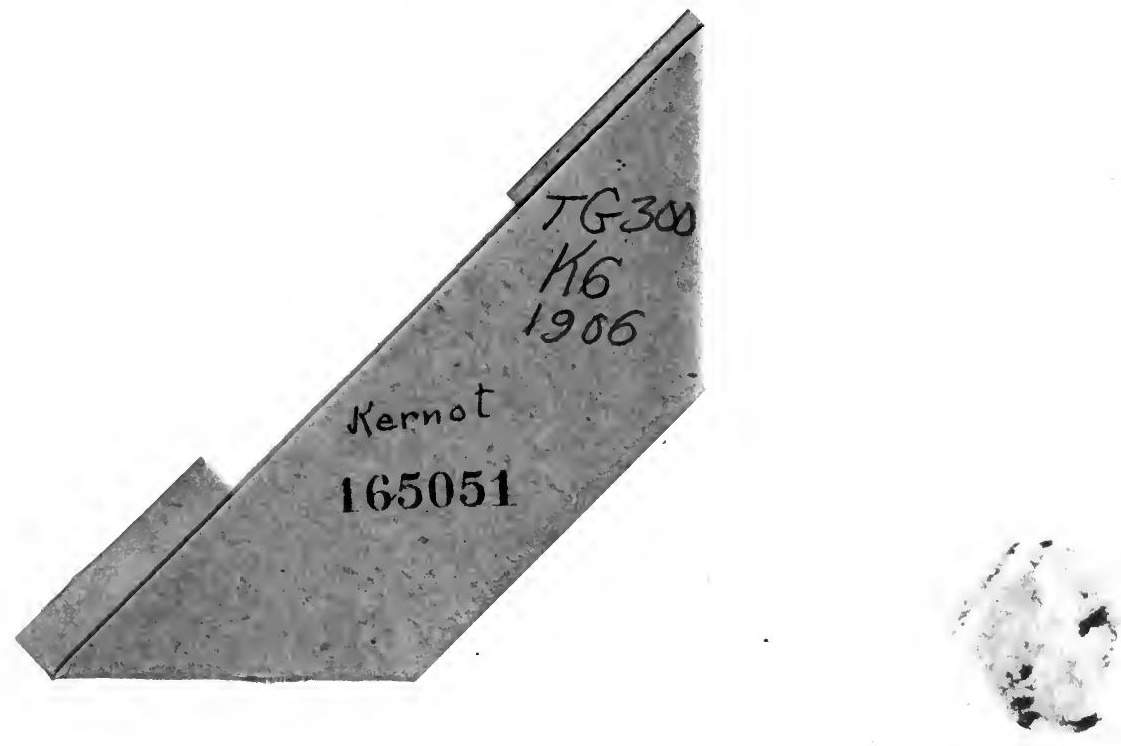


